\title{
NASA Team 2 Sea Ice Concentration Algorithm Retrieval Uncertainty
}

\author{
Ludovic Brucker, Donald J. Cavalieri, Thorsten Markus, and Alvaro Ivanoff
}

\begin{abstract}
Satellite microwave radiometers are widely used to estimate sea ice cover properties (concentration, extent, and area) through the use of sea ice concentration (IC) algorithms. Rare are the algorithms providing associated IC uncertainty estimates. Algorithm uncertainty estimates are needed to assess accurately global and regional trends in IC (and thus extent and area), and to improve sea ice predictions on seasonal to interannual timescales using data assimilation approaches. This paper presents a method to provide relative IC uncertainty estimates using the enhanced NASA Team (NT2) IC algorithm. The proposed approach takes advantage of the NT2 calculations and solely relies on the brightness temperatures (TBs) used as input. NT2 IC and its associated relative uncertainty are obtained for both the Northern and Southern Hemispheres using the Advanced Microwave Scanning Radiometer for the Earth Observing System (AMSR-E) TB. NT2 IC relative uncertainties estimated on a footprint-by-footprint swath-by-swath basis were averaged daily over each $12.5-\mathrm{km}$ grid cell of the polar stereographic grid. For both hemispheres and throughout the year, the NT2 relative uncertainty is $<5 \%$. In the Southern Hemisphere, it is low in the interior ice pack, and it increases in the marginal ice zone up to $5 \%$. In the Northern Hemisphere, areas with high uncertainties are also found in the high IC area of the Central Arctic. Retrieval uncertainties are greater in areas corresponding to NT2 ice types associated with deep snow and new ice. Seasonal variations in uncertainty show larger values in summer as a result of melt conditions and greater atmospheric contributions. Our analysis also includes an evaluation of the NT2 algorithm sensitivity to AMSR-E sensor noise. There is a $60 \%$ probability that the IC does not change (to within the computed retrieval precision of $1 \%$ ) due to sensor noise, and the cumulated probability shows that there is a $90 \%$ chance that the IC varies by less than $\pm 3 \%$. We also examined the daily IC variability, which is dominated by sea ice drift and ice formation/melt. Daily IC variability is the highest, year round, in the MIZ (often up to $20 \%$, locally $30 \%$ ). The temporal and spatial distributions of the retrieval uncertainties and the daily IC variability is expected to be
\end{abstract}

Manuscript received May 22, 2013; revised November 5, 2013 and February 7, 2014; accepted March 10, 2014.

L. Brucker is with NASA Goddard Space Flight Center, Cryospheric Sciences Laboratory, Greenbelt, MD 20771 USA, and also with Universities Space Research Association, Goddard Earth Sciences Technology and Research Studies and Investigations, Columbia, MD 21044-3432 USA (e-mail: ludovic. brucker@nasa.gov).

D. J. Cavalieri is with Sandy Spring, MD 20860 USA, and also with Cryospheric Sciences Laboratory, NASA Goddard Space Flight Center, Greenbelt, MD 20771 USA (e-mail: Donald.J.Cavalieri@nasa.gov).

T. Markus is with Cryospheric Sciences Laboratory, NASA Goddard Space Flight Center, Greenbelt, MD 20771 USA (e-mail: thorsten.markus@nasa.gov).

A. Ivanoff is with ADNET Systems, Inc. Rockville, MD 20852 USA, and also with Cryospheric Sciences Laboratory, NASA Goddard Space Flight Center, Greenbelt, MD 20771 USA (e-mail: alvaro.ivanoff@nasa.gov).

Color versions of one or more of the figures in this paper are available online at http://ieeexplore.ieee.org.

Digital Object Identifier 10.1109/TGRS.2014.2311376 useful for algorithm intercomparisons, climate trend assessments, and possibly IC assimilation in models.

Index Terms-Measurement uncertainty, passive microwave remote sensing, sea ice.

\section{INTRODUCTION}

$\mathbf{S}$ EA ice plays a major role in the Earth's climate system and is an important indicator of its changes. The sharp and dramatic reduction in Arctic sea ice extent over the last decades has made sea ice one of the most visible and wellknown indicators of climate change. The polar sea ice cover has several important characteristics such as its extent, concentration, thickness, drift, and freeze-up/melt-onset dates. Our knowledge of many of these sea ice characteristics as well as the seasonal, regional, and long-term changes of the global sea ice cover itself has been obtained through the use of satellite microwave imaging radiometers.

In 2002, NASA launched the Aqua satellite with the Advanced Microwave Scanning Radiometer for the Earth Observing System (AMSR-E), which is built by the JAXA. AMSR-E had a higher spatial resolution than any of the previous spaceborne imaging radiometers. The 3 -dB AMSR-E footprint dimensions vary from $27.4 \mathrm{~km} \times 15.7 \mathrm{~km}$ at $18.7 \mathrm{GHz}, 31.5 \mathrm{~km} \times$ $18.1 \mathrm{~km}$ at $23.8 \mathrm{GHz}$, and $14 \mathrm{~km} \times 8 \mathrm{~km}$ at $36.5 \mathrm{GHz}$, to $5.9 \mathrm{~km} \times 3.5 \mathrm{~km}$ at $89 \mathrm{GHz}$ [1]. These spatial resolutions, up to $\sim 2.5$ times finer than that from the Special Sensor Microwave/Imager, enable sea ice products to be gridded at a grid cell resolution of $12.5 \mathrm{~km}$ (versus $25 \mathrm{~km}$ before). Since May 2012, the JAXA Global Change Observation Mission 1stWater/AMSR2 operates with a finer spatial resolution than AMSR-E, enabling sea ice products to be produced at a grid cell resolution of $10 \mathrm{~km}$ or less.

While all of the aforementioned sea ice characteristics are needed to understand and to quantify the observed climate changes at high latitudes, this study focuses on sea ice concentration (IC) uncertainties obtained with the NT2 IC algorithm [2], [3]. The NT2 algorithm provided operational daily IC for AMSR-E and has been selected as a research algorithm for AMSR2. The AMSR-E sea ice products are distributed and archived by the U.S. National Snow and Ice Data Center (NSIDC). NT2 is also used operationally by the U.S. National Ice Center, and by NOAA's Marine Modeling and Analysis Branch of the Environmental Modeling Center at the National Centers for Environmental Prediction.

The utility of spaceborne IC retrievals depends on both their precision and accuracy. Retrieval accuracy is assessed generally from spaceborne, airborne, and in situ validation studies, which are limited in both area and time. In contrast to the NT2 
IC validation studies previously undertaken in the Arctic [4], [5] and the Antarctic [6], [7], this paper provides retrieval uncertainty estimates corresponding to each IC retrieval on a footprint-by-footprint basis.

Retrieval uncertainty estimates are needed for both operational (marine and offshore activities) and scientific applications (e.g., heat flux calculations, sea ice volume estimations, and climate trend assessments). Retrieval uncertainty estimates are also needed to improve sea ice predictions on seasonal to interannual timescales using data assimilation approaches. While IC is a key component of sea ice modeling, the use of satellite observations within the models has generally been limited because of the lack of retrieval uncertainty estimates [8]. All data assimilation approaches (based on either deterministic or ensemble schemes) require explicit estimates of observation error (i.e., estimates of IC uncertainty) to derive the optimal initial state. Thus, IC retrieval uncertainty estimates from satellite imaging microwave radiometers are crucial to perform higher quality data assimilation.

Among the existing IC algorithms using microwave radiometer observations as inputs, rare are the ones providing IC with an associated uncertainty estimate. The Environment Canada's Ice Concentration Extractor provides IC retrievals in conjunction with a confidence level [9]. The confidence level is a unitless measure based on the mean absolute deviation of IC retrievals for a set of 2000 built-in tie points. The European Organisation for the Exploitation of Meteorological Satellites Ocean and Sea Ice Satellite Application Facility provides IC retrieval uncertainties. Specifications are described in the product user manual [10]. The IC uncertainty results from a combination of instrument errors, algorithm and tie-point uncertainties, and a simulated representativeness error to deal with the different frequency-dependent footprint sizes.

In response to the need for IC retrieval uncertainties, this paper provides for the NT2 algorithm relative IC retrieval uncertainty estimates calculated on a footprint-by-footprint basis for swath and daily averaged NT2 IC retrievals for both the Northern and Southern Hemispheres using a statistical approach. It also provides a measure of daily IC variability. In Section II, we briefly discuss the NT2 IC algorithm. Our results are presented in Section III, including the retrieval uncertainties resulting from AMSR-E sensor noise, and algorithm retrieval precision (Section III-A). The NT2 retrieval uncertainty estimates are presented Section III-B. In Section III-C, we compare these uncertainty estimates to some NT2 ice types. The daily IC variability is detailed in Section III-D. In Section IV, we draw our conclusions.

\section{NT2 IC ALGORITHM}

A detailed description of the NT2 basis was provided in [2] and [3]. Therefore, only a summary of the operational version of the algorithm is presented here, as needed to describe the proposed method for deriving the NT2 IC retrieval uncertainty.

\section{A. Algorithm Description}

The NT2 IC algorithm uses both satellite observed and simulated microwave brightness temperatures (TBs) to iterate on a solution for IC. The simulated TBs were computed with an atmospheric forward radiative transfer model [11] using 12 different winter and summer atmospheric temperature and humidity profiles based on the Antarctic Georg von Neumayer weather station climatology [12], together with different cloud types from cirrus to cumulus congestus ([13, table I]). The NT2 algorithm implicitly assumes that the climatological range of temperatures and atmospheric properties are similar in both the Arctic and Antarctic, which may not fully characterize the changing summer Arctic atmosphere (warmer and more humid). The NT2 uses, in addition, surface microwave emissivities taken from [14], with different assumed surface temperatures: $271 \mathrm{~K}$ (open water), $268 \mathrm{~K}$ (summer sea ice), and $248 \mathrm{~K}$ (winter sea ice). These simulated TBs, for different atmospheric profiles and surface emissivities and temperatures, are used to build lookup tables. The NT2 radiometric variables are ratios of TBs based on four AMSR-E frequencies at one of two polarizations (vertical $\mathrm{V}$ or horizontal $\mathrm{H}$ ): $18.7 \mathrm{~V}, 18.7 \mathrm{H}$, $23.8 \mathrm{~V}, 36.5 \mathrm{~V}, 89 \mathrm{~V}$, and $89 \mathrm{H} \mathrm{GHz}$. These ratios are the gradient ratio (GR), defined by TBs at two frequencies $f_{1}$ and $f_{2}\left(f_{1}>f_{2}\right)$ and the same polarization $p$ [see (1)]; the polarization ratio (PR), defined by TBs at the same frequency $f$ but different polarizations [see (2)]; and $\Delta$ GR [see (3)]. In NT2, the PRs are "rotated", which means they are calculated using a combination with $\mathrm{GR}_{36.5,18.7}^{\mathrm{V}}$ [2]. The GR and PR values can change with IC, and the properties of the snow cover (e.g., depth and layering).

$$
\begin{aligned}
\mathrm{GR}_{f_{1}, f_{2}}^{p} & =\frac{T_{B_{f_{1}}}^{p}-T_{B_{f_{2}}}^{p}}{T_{B_{f_{1}}}^{p}+T_{B_{f_{2}}}^{p}} \\
\mathrm{PR}_{f} & =\frac{T_{B_{f}}^{\mathrm{V}}-T_{B_{f}}^{\mathrm{H}}}{T_{B_{f}}^{\mathrm{V}}+T_{B_{f}}^{\mathrm{H}}} \\
\Delta \mathrm{GR} & =\mathrm{GR}_{89,18.7}^{\mathrm{H}}-\mathrm{GR}_{89,18.7}^{\mathrm{V}} .
\end{aligned}
$$

The algorithm permits the identification of the following ice types: FY/MY ice, and ice type C. FY/MY indicates either first-year ice or multiyear ice. In NT2, ice type C can refer either to sea ice with radiometric properties characteristics of a deep snow cover, or new ice [2]. A $\mathrm{GR}_{36.5,18.7}^{\mathrm{V}}$ threshold value of -0.01 decides between the use of TB lookup tables for ice type $\mathrm{C} / \mathrm{deep}$ snow, or ice type $\mathrm{C} /$ new ice. The rationale of using a $\mathrm{GR}_{36.5,18.7}^{\mathrm{V}}$ threshold may be found in [15], and its value differentiates between areas of new and young ice types typically found in seasonal sea ice zones, and areas of first-year and multiyear ice types typically found in the central Arctic and around Antarctica. Coastal polynyas (with a reasonable size compared with the footprint dimensions) also satisfy the $\mathrm{GR}_{36.5,18.7}^{\mathrm{V}}$ threshold for new ice, if sea ice is present.

Using the atmospheric radiative transfer model, TBs are simulated for ICs varying between $0 \%$ and $100 \%$ (providing 101 IC values in $1 \%$ steps). Simulated TBs are used to compute the three radiometric quantities described above [see (1)-(3)], which are stored in lookup tables. There are a total of $101 \times$ $101 \times 12$ (i.e., 112211) combinations associated with two different sea-ice types (FY/MY, and C), and the 12 atmospheric profiles. Ratios calculated using simulated TBs are named simulated ratios, and those calculated using observed TBs are 
named observed ratios. The difference between the observed and simulated ratios is $\delta \mathrm{R}$, calculated as follows:

$$
\begin{aligned}
\delta \mathrm{R}=\left(\mathrm{PR}_{18.7}^{\mathrm{obs}}-\mathrm{PR}_{18.7}^{\mathrm{sim}}\right)^{2}+ & \left(\mathrm{PR}_{89}^{\mathrm{obs}}-\mathrm{PR}_{89}^{\mathrm{sim}}\right)^{2} \\
+ & \left(\Delta \mathrm{GR}^{\mathrm{obs}}-\Delta \mathrm{GR}^{\mathrm{sim}}\right)^{2} .
\end{aligned}
$$

The lower $\delta \mathrm{R}$, the better the agreement between the observed and simulated ratios. The estimated NT2 IC is an integer value between 0 and 100, and corresponds to the concentration associated with the smallest $\delta \mathrm{R}$ [see (4)], named $\delta \mathrm{R}_{\min }$.

\section{B. Analysis of $\delta \mathrm{R}_{\min }$}

For a given set of TBs, the NT2 ICs corresponding to the 100 smallest $\delta \mathrm{R}$, as well as their values, are shown in Fig. 1 for three different Arctic regions: the Central Arctic, Lincoln Sea, and Baffin Bay. These regions have different sea ice properties (e.g., multiyear ice and ice from the MIZ) with different ICs. ICs are represented as a stairstep graph for consistency with the NT2 IC retrieval precision of $1 \%$. The $\delta \mathrm{R}_{N}$ values range in magnitude from $10^{-6}$ to $10^{-4}$. In high IC areas, ICs estimates for $N \leq 20$ are within $1 \%$ [see Fig. 1(a) and (b)]. In contrast, in the MIZ, where concentrations are lower, IC values for the 20 smallest $\delta \mathrm{R}$ are more variable, within $\pm 4 \%$ [see Fig. 1(c)]. IC retrieval in the MIZ is challenging because the sea ice cover is fractured, discontinuous, and often composed by a mixture of ice types (e.g., new ice, nilas, pancakes). Moreover, the emissivity of these ice types is low, increasing the atmospheric contributions. Therefore, because of the high variability of sea ice characteristics in MIZs (and thus microwave emissivity), it is not surprising to find more variable NT2 IC retrievals for the 20 smallest $\delta \mathrm{R}$.

An intuitive approach to characterize the uncertainty of the NT2 IC retrievals would be to analyze the $\delta R_{\text {min }}$ values. However, $\delta \mathrm{R}$ [see (4)] is a sum of the differences of various radiometric quantities and is not directly associated with specific sea ice properties. Additionally, $\delta \mathrm{R}_{\min }$ values are not higher in the MIZ where larger uncertainties than in high IC areas, are expected in the NT2 IC retrievals than in high IC areas (see Fig. 2). In this paper, $\delta \mathrm{R}_{\min }$ values are not used to quantify the NT2 IC retrieval uncertainties. Nonetheless, the spatial distribution of $\delta \mathrm{R}_{\min }$ (see Fig. 2) provides us with some guidance for future algorithm improvements. The spatial distribution of $\delta \mathrm{R}_{\min }$ in the Arctic and Antarctic (see Fig. 2) shows that there are areas better represented by the simulated NT2 lookup tables than others. Overall, $\delta \mathrm{R}_{\min }$ is small. The $\delta \mathrm{R}_{\min }$ is the highest over Antarctic sea ice during the summer months, particularly in the Weddell Sea (East of the Peninsula). In the Arctic, the highest $\delta \mathrm{R}_{\text {min }}$ values are located over the multiyear ice from June to September; however, they are up to four times smaller than over Antarctic sea ice most of the year.

Some of the high $\delta \mathrm{R}_{\min }$ values are likely related to atmospheric effects and may reflect limitations of the atmospheric climatological values used in the model. The atmospheric contribution is larger over low emissivity surfaces (e.g., multiyear ice and sea ice with melt ponds) than high emissivity surfaces (e.g., seasonal and first-year ice). The atmospheric contribution is also larger in summer than in winter due to a substantially larger cloud liquid water content [16], [17]. Other high $\delta \mathrm{R}_{\min }$

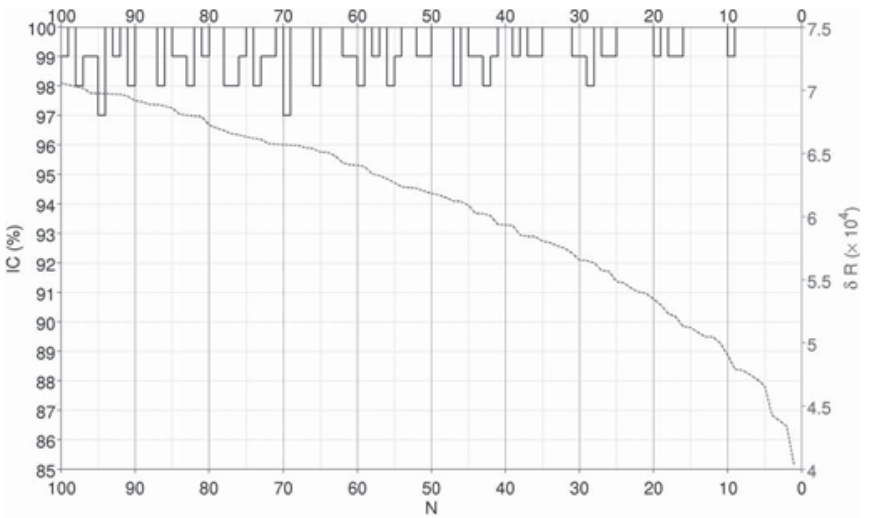

(a)

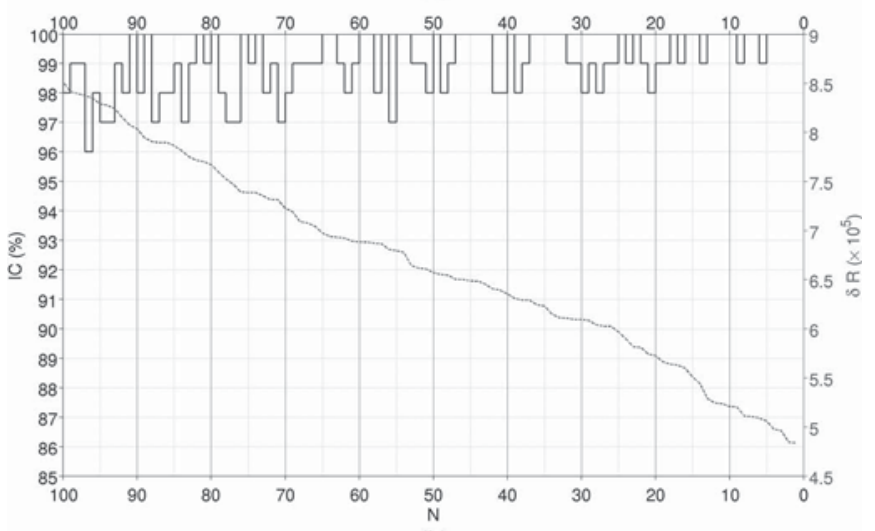

(b)

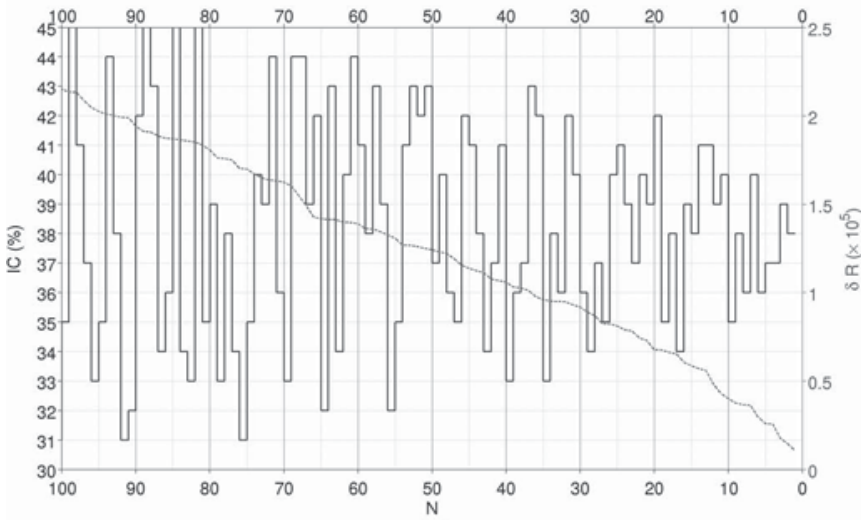

(c)

Fig. 1. NT2 ICs (black stairstep plot with values on the left ordinate axis) corresponding to the 100 smallest $\delta \mathrm{R}$ (gray dashed curve with values on the right ordinate axis), on January 15, 2010. The abscissa represents $N$. The vertical axis scales were optimized in each panel, which corresponds to different Arctic regions. (a) Central Arctic (E). (b) Lincoln Sea (D). (c) Baffin Bay (A). [see Fig. 3(b) for the localization].

values appear to be ice-type dependent and may reflect limitations of the specific ice-type emissitivites used in the model. This could be investigated in a future study using scatterometer observations (e.g., QuikSCAT/SeaWinds during the AMSR-E era and OceanSat-2/OSCAT during the AMSR2 era) and additional satellite sea ice products.

Note that the $\delta \mathrm{R}_{\min }$ values are low in the MIZs year round in both hemispheres. Therefore, the set of simulated ratios closely match the observed ratios in the MIZ. Since it is expected that the IC uncertainty retrievals are larger in the MIZs, the use of $\delta \mathrm{R}_{\min }$ as a measure of uncertainty is not possible yet. Further work is needed to relate the $\delta \mathrm{R}_{\min }$ value to geophysical 


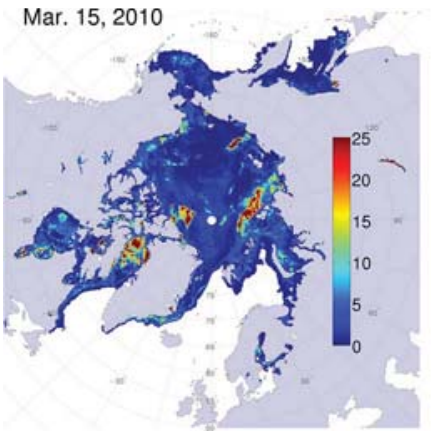

(a)

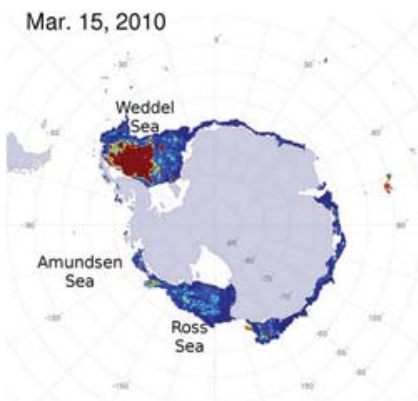

(c)

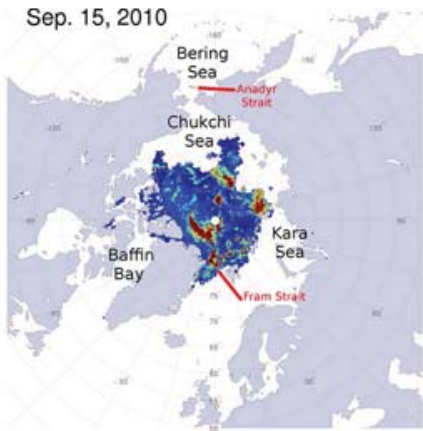

(b)

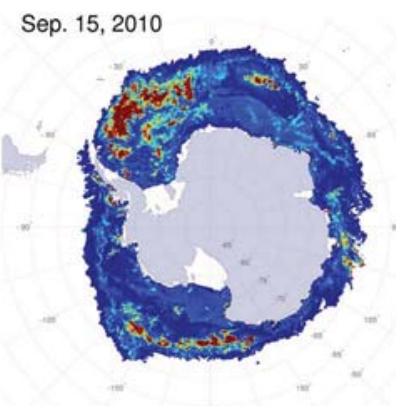

(d)
Fig. 2. $\delta \mathrm{R}_{\min }\left(\times 10^{5}\right)$ on March 15 and September 15, 2010. (a) and (b) Northern Hemisphere. (c) and (d) Southern Hemisphere. Maps (b) and (c) also illustrate the approximate locations of Seas and Straits mentioned in this paper. Anadyr Strait is between the continent and St. Lawrence Island.

properties characterizing the ice cover, or the state of the atmosphere. The approach selected to provide a measure of the NT2 IC uncertainty, which is presented hereafter, is thus independent of $\delta \mathrm{R}_{\min }$.

\section{Relationship Between IC Relative Uncertainty and $N$}

The NT2 algorithm calculates $112211 \delta \mathrm{R}$, and uses the smallest one to determine the retrieved IC. By its design, NT2 enables us to investigate the IC retrieval uncertainty by analyzing the ICs associated with the $N$ smallest $\delta \mathrm{R}_{s}$. In this paper, retrieval uncertainty is defined as the standard deviation of the $N$ ICs corresponding to the $N$ smallest $\delta \mathrm{R}_{s}$. The choice of $N$ is arbitrary, and different values of $N$ are now considered to establish a measure of the NT2 uncertainty. This statistical approach provides a useful measure of uncertainty inherent to the algorithm, but it provides neither a measure of precision nor of accuracy. Several previous studies assessed the accuracy of NT2 retrievals [4], [7], and an estimate of precision is carried out in Section III-A.

Fig. 3(a) shows the standard deviation of IC retrievals $\left(\sigma_{N}\right)$ for different values of $N$ for five different regions, with different sea ice types. In every region, $\sigma_{N}$ tends to increase with $N$. The increase in $\sigma_{N}$ as a function of $N$ is steeper in the MIZ (gray curves) than in regions north of Greenland (black curves). The fact that the MIZ is characterized by a variety of sea ice types, and strong surface and atmospheric heterogeneities, including cloud liquid water gradients, all of which may be found at scales smaller than the 3-dB AMSR-E footprint, may explain the steep increase in $\sigma_{N}$ for $N$ ranging between 1 and 100. For the two areas north of Greenland, $\sigma_{N}$ values are small $(\leq 1 \%)$,

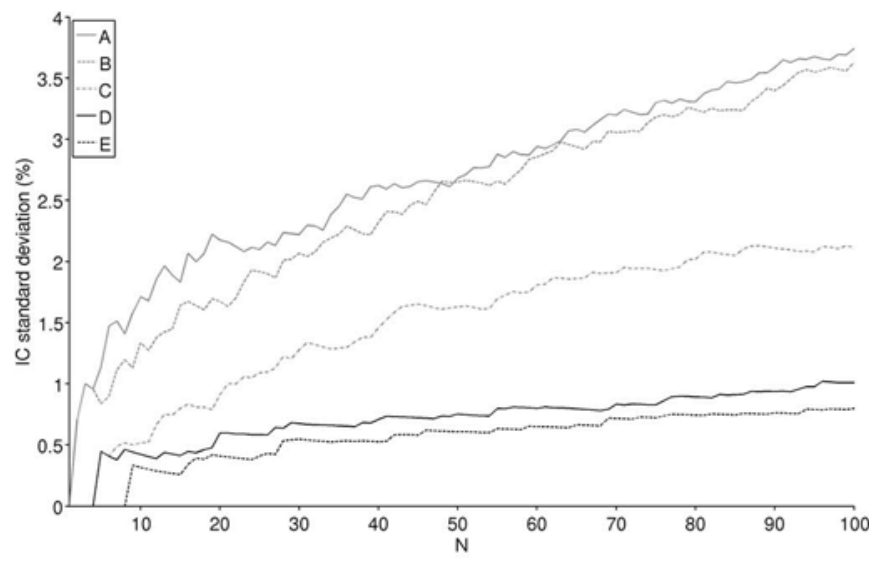

(a)

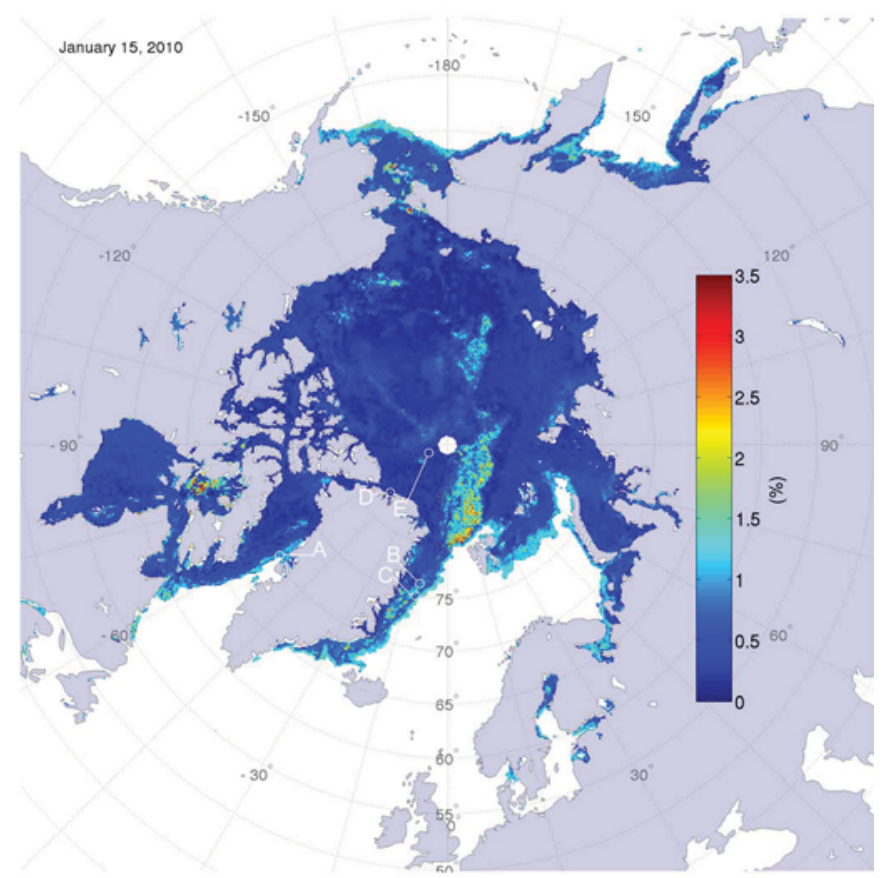

(b)

Fig. 3. (a) Standard deviation of the IC $\left(\sigma_{N}\right)$ corresponding to the $N$ smallest $\delta \mathrm{R}$ calculated with one-footprint $\mathrm{TB}$ observations recorded in five different regions indicated in the Fig. 3(b) map. (b) Map of $\sigma_{50}-\sigma_{20}$ for January 15, 2010 , with the locations of the five different regions (white).

whereas $\sigma_{N}$ is between about $0.5 \%-3.7 \%$ for the three MIZ areas. In all of these regions, (using $N$ up to 10000 , not shown) there is no characteristic evolution of $\sigma_{N}$ as a function of $N$ (e.g., plateau and step function), which could be used for identifying a threshold for $N$. As noted earlier, the selection of $N$ is arbitrary, providing a relative IC uncertainty.

Fig. 3(b) shows the spatial distribution of $\sigma_{50}-\sigma_{20}$. Overall, the differences are small $(0.1 \%-1.5 \%)$ across the Arctic basin. Therefore, the choice of $N$ is not critical for a relative algorithm uncertainty. In the following, we provide a quantitative analysis of the influence of $N$. For conditions typical of winter and summer (melting snow and sea ice), and autumn (new ice formation), the following three dates were considered: March 15, June 15, and October 15, 2010; representing a total of 205939 grid cells. For each of these dates, daily gridded $\sigma_{N}$ was calculated for the entire Northern Hemisphere sea ice using $N$ equal to $20,35,50$, and 100 . Table I presents the mode, and 
TABLE I

Mode, Mean $\bar{X}$, and Standard Deviation of the Ratio $\sigma_{N} / \sigma_{20}$, With $N=35,50$, And 100 , For the 15 Th of March, June, AND OCTOBER OVER THE NORTHERn Hemisphere SEA ICE

\begin{tabular}{c|c|c|c|c|c|c|c|c|c|c|c|c|}
\hline & \multicolumn{3}{|c|}{ March 15 } & \multicolumn{3}{c|}{ June 15} & \multicolumn{3}{c|}{ October 15} & \multicolumn{3}{c|}{ All 3 dates } \\
\hline & $\sigma_{35} / \sigma_{20}$ & $\sigma_{50} / \sigma_{20}$ & $\sigma_{100} / \sigma_{20}$ & $\sigma_{35} / \sigma_{20}$ & $\sigma_{50} / \sigma_{20}$ & $\sigma_{100} / \sigma_{20}$ & $\sigma_{35} / \sigma_{20}$ & $\sigma_{50} / \sigma_{20}$ & $\sigma_{100} / \sigma_{20}$ & $\sigma_{35} / \sigma_{20}$ & $\sigma_{50} / \sigma_{20}$ & $\sigma_{100} / \sigma_{20}$ \\
\hline Mode & 1.3 & 1.5 & 2.2 & 1.3 & 1.5 & 2.2 & 1.3 & 1.5 & 2.2 & 1.3 & 1.5 & 2.2 \\
$\bar{X} \pm$ Stdev & $1.2 \pm 0.1$ & $1.4 \pm 0.2$ & $1.7 \pm 0.4$ & $1.3 \pm 0.1$ & $1.5 \pm 0.2$ & $1.9 \pm 0.4$ & $1.3 \pm 0.1$ & $1.5 \pm 0.2$ & $1.8 \pm 0.4$ & $1.2 \pm 0.1$ & $1.4 \pm 0.2$ & $1.8 \pm 0.4$ \\
\hline
\end{tabular}

mean ratio of $\sigma_{N} / \sigma_{20}$, with $N=35,50$, and 100 . The modes increase as $N$ increases, and are $1.3,1.5$, and 2.2 , respectively. They are independent of the dates and therefore are likely independent of the ice conditions. The mean and ranges of the ratios are also fairly independent of the ice conditions. The ranges increase as $N$ increases, from $1 \%-1.85 \%$ and $1 \%-2.25 \%$, to $1 \%-3 \%$. The statistics of these ratio values can be used to obtain an estimate of the relative NT2 IC retrieval uncertainty for another $N$. While the relative NT2 IC retrieval uncertainty depends on $N$, our analysis confirms that the precise value of $N$ is not critical in obtaining a useful measure of uncertainty. However, $N$ cannot be too large since high $N$ corresponds to high $\delta \mathrm{R}$ and therefore to a weak agreement between the observed and simulated radiometric ratios. In this paper, $N$ was set to 20, and hereafter $\sigma_{20}$ is used as our definition of the NT2 relative IC uncertainty. This uncertainty is relative to $N$ (i.e., not absolute). Furthermore, a consistent value of $N$ enables an easy comparison among regions, days, and hemispheres.

\section{RESULTS}

Here, we discuss some of the uncertainties associated with the NT2 daily averaged IC product. These include uncertainties associated with the AMSR-E sensor noise, algorithm retrieval precision, and uncertainties inherent to the NT2 algorithm itself. We also examine the daily IC variation by presenting the standard deviation of all of the IC estimates at the footprint level within each grid cell. This paper is specific to the NT2 algorithm; thus, we do not address gridding uncertainties, which are common to every gridded product.

\section{A. Retrieval Uncertainties Resulting From AMSR-E Sensor Noise and Algorithm Retrieval Precision}

The AMSR-E channels used in the NT2 algorithm are $18.7 \mathrm{~V} /$ $\mathrm{H}, 23.8 \mathrm{~V}, 36.5 \mathrm{~V}$, and $89 \mathrm{~V} / \mathrm{H}$. The corresponding noise equivalent $\Delta \mathrm{T}(\mathrm{NE} \Delta \mathrm{T})$ values for these channels are $<0.7 \mathrm{~K}$ at $18.7 \mathrm{~V} / \mathrm{H}$ and $36.5 \mathrm{~V},<0.6 \mathrm{~K}$ at $23.8 \mathrm{~V}$, and $<1.4 \mathrm{~K}$ for the horn B at $89 \mathrm{~V} / \mathrm{H}$ [18]. To quantify the effect of AMSR-E noise on the estimated ICs, NT2 was run several times using: 1) AMSR-E/Aqua Level 2 A (L2A) Global Swath Spatially Resampled TBs [19] for the reference simulation; and 2) these L2A TBs with the extremum NE $\Delta \mathrm{T}$ values of $\pm 0.7 \mathrm{~K}$ at 18.7 and $36.5 \mathrm{GHz}, \pm 0.6 \mathrm{~K}$ at $23.8 \mathrm{GHz}$, and $\pm 1.4 \mathrm{~K}$ at $89 \mathrm{GHz}$. The L2A TBs, whose footprint observations are matched to the same antenna pattern using Backus-Gilbert interpolation, were extracted from one swath recorded on January 15, 2010. In the Northern Hemisphere, there were a total of 47981 footprint observations with IC retrievals. For each footprint and each channel, three noise values were considered to cover the range of possibilities $(-\mathrm{NE} \Delta \mathrm{T}, 0$, and $+\mathrm{NE} \Delta \mathrm{T})$. Since the NT2 algorithm uses six channels, a total of $3^{6}(=729)$ NT2 runs were done per footprint (i.e., a total of $34.97 \times 10^{6}$ iterations).

The result, obtained using the Northern Hemisphere wintertime swath with IC mostly over $95 \%$, shows that, for $60 \%$ of the iterations, the NT2 IC estimates remain the same (see Fig. 4). The probability of an absolute IC change of $1 \%(3 \%)$ is $15 \%$ (8\%), and the cumulated probability [Fig. 4(b)] shows there is a $75 \%$ (and 90\%) chance that the IC varies by less than $\pm 1 \%$ (and $\pm 3 \%$ ) due to sensor noise. The standard deviation of the distribution of probabilities [see Fig. 4(a)] is $2.2 \%$. If no noise is considered for the $89-\mathrm{GHz}$ channels, which have the largest $\mathrm{NE} \Delta \mathrm{T}$, the distribution of probabilities is narrower, and the standard deviations drops to $1.6 \%$. To span the entire range of TBs and ICs, a similar experiment was performed using the summer-time TBs of the Southern Hemisphere collected during the same swath. ICs ranged between $30 \%$ and $100 \%$. Very similar contributions from the sensor noise were obtained using these TBs. The standard deviation of the distribution of probabilities was, however, slightly larger (3.5\%), but no changes appeared on the range of IC differences. These simulations, carried out on an entire swath including both the Northern and Southern Hemispheres, highlight the moderate probability that the AMSR-E NE $\Delta$ T significantly affects the NT2 IC retrievals.

Next, the footprint-to-footprint variability in terms of both TBs and IC estimates are analyzed. To this end, we take advantage of the fact that the Aqua polar orbiting spacecraft makes multiple orbits per day, and that the AMSR-E scanning sensor is able to monitor a given area at high latitudes several times per day. AMSR-E records observations every 10.1/9 km along/across track at frequencies lower than $89 \mathrm{GHz}$, and every 4.1/4.5 km along/across track at $89 \mathrm{GHz}$ [18]. Within the same scan, the longest time elapsed between one footprint observations and the next (i.e., across-track) is $2.6 \mathrm{~ms}$. With a nominal rotation speed of $40 \mathrm{r} / \mathrm{min}$, the time elapsed from one scan to the next (i.e., along track) is $\sim 1.5 \mathrm{~s}$. Thus, the temporal variability of sea ice can be neglected when using adjacent footprint observations over a limited area, both along and across track for a given swath. This allows us to quantify the NT2 retrieval precision by examining IC estimates footprint-by-footprint in areas with a homogeneous sea ice cover. Here, the approach is quite similar to the retrieval uncertainties resulting from sensor noise, but using observed TBs.

The area selected to assess the NT2 retrieval precision is in the Kara Sea, because it displayed a minimum spatial heterogeneity and had a sufficiently large number of footprint observations. The area was covered by seven AMSR-E swaths 


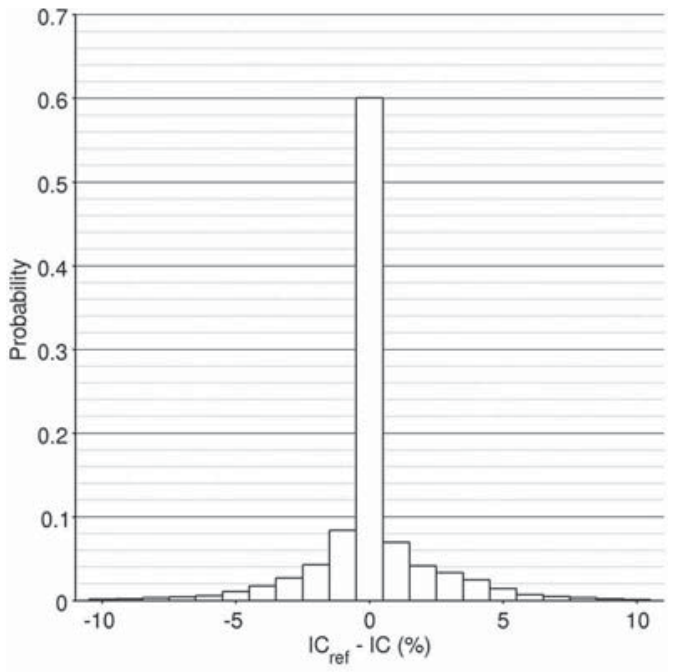

(a)

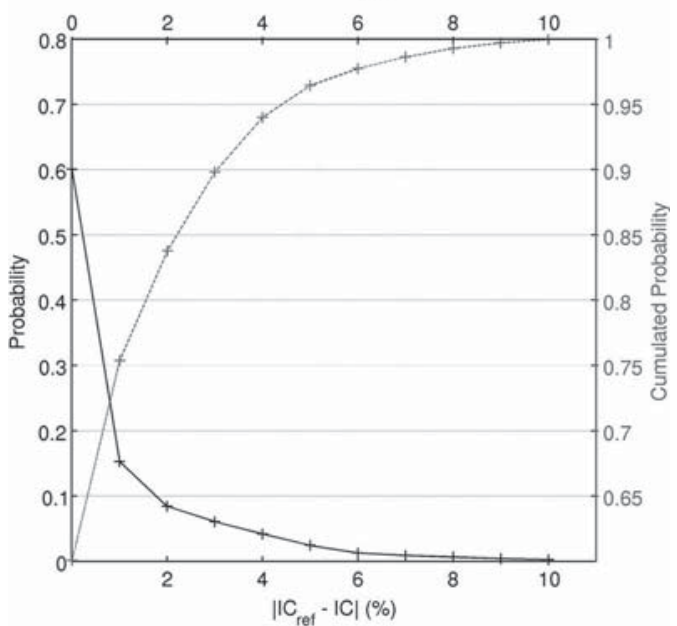

(b)

Fig. 4. (a) Distribution of probabilities that the NT2 IC retrievals change due to the AMSR-E sensor noise (NE $\Delta \mathrm{T}$ ) on the TBs. (b) Probabilities associated to an absolute value of IC change (left ordinate axis, black curve), along with the cumulated probability (right ordinate axis, black curve). L2A TB observations recorded over the Northern Hemisphere during the ascending orbit on January 15,2010 (starting at 23:43) were used.

on March 15, 2010, and the number of footprints per swath within the area ranged from 42 to 85 . Table II provides for each swath the minimum, maximum, mean, and standard deviation of the following parameters: IC and TBs at $18.7 \mathrm{~V} / \mathrm{H}, 36.5 \mathrm{~V}$, and $89 \mathrm{~V} / \mathrm{H}$. The IC standard deviations for the seven swaths are extremely low, varying from $0 \%$ to $0.4 \%$ (see Table II). These results demonstrate that, over a uniform sea ice cover, the NT2 algorithm retrievals have high precision. Although there is at least some geophysical footprint-to-footprint spatial variability, these results represent our best estimate of retrieval precision.

As noted previously, the operational version of the NT2 algorithm is based on a comparison between observed and simulated TB ratios; thus, the solutions are constrained to values between $0 \%$ and $100 \%$. In [20], the algorithm was modified to evaluate the effect of these constraints. It is possible that some combination of TBs would result in IC greater than $100 \%$ given the algorithms specific set of simulated TB ratios. Ice concentrations greater than $100 \%$ would manifest itself as an area of high
TABLE II

Minimum, Maximum, Mean and Standard Deviation of IC Values FOR EACH SWATH COVERING AN AREa IN THE Kara SEA ON MARCH 15, 2010. THE SWATH ID AND THE NUMBER OF FoOTPRINTS CONSIDERED ARe Indicated IN the First Column. This Particular AREa Is Covered by a Total of Seven Swaths During the 24-h Period. The Standard Deviation For Each Swath (Last Column) Is a Measure of the SPatial Variability for This AREa. IC Values Are Expressed in Percentage, AND TB in Kelvin

\begin{tabular}{|c|c|c|c|c|c|}
\hline Swath No./Footprints & Parameter & Min & $\operatorname{Max}$ & Mean & $\overline{\text { Stdev }}$ \\
\hline \multirow[t]{6}{*}{$0109 \mathrm{D} / 61$} & Ice Con & 97 & 100 & 99.93 & 0.4 \\
\hline & V18 & 249.28 & 252.71 & 251.2 & 0.7 \\
\hline & V36 & 247.45 & 249.12 & 248.11 & 0.43 \\
\hline & V89 & 234.3 & 242.74 & 238.29 & 2.22 \\
\hline & H18 & 230.04 & 235.46 & 232.84 & 0.91 \\
\hline & H89 & 220.91 & 229.25 & 224.98 & 2.34 \\
\hline \multirow[t]{6}{*}{$0248 \mathrm{D} / 70$} & Ice Con & 100 & 100 & 100 & 0 \\
\hline & V18 & 249.89 & 253.01 & 251.62 & 0.68 \\
\hline & V36 & 247.47 & 249.55 & 248.31 & 0.44 \\
\hline & V89 & 235.8 & 242.02 & 238.66 & 1.93 \\
\hline & H18 & 230.28 & 234.96 & 233.35 & 0.91 \\
\hline & H89 & 222.78 & 229.85 & 225.94 & 1.94 \\
\hline \multirow[t]{6}{*}{$0337 \mathrm{~A} / 52$} & Ice Con & 100 & 100 & 100 & 0 \\
\hline & V18 & 249.82 & 252.79 & 251.57 & 0.73 \\
\hline & V36 & 247.36 & 249.27 & 248.32 & 0.43 \\
\hline & V89 & 234.86 & 241.84 & 238.42 & 1.99 \\
\hline & H18 & 232.22 & 235.26 & 233.71 & 0.76 \\
\hline & H89 & 222.41 & 229.21 & 226.29 & 2 \\
\hline \multirow[t]{6}{*}{$0516 \mathrm{~A} / 42$} & Ice Con & 99 & 100 & 99.98 & 0.15 \\
\hline & V18 & 250.12 & 252.97 & 251.66 & 0.64 \\
\hline & V36 & 247.6 & 249.37 & 248.47 & 0.39 \\
\hline & V89 & 236.46 & 242.85 & 239.16 & 1.45 \\
\hline & H18 & 232.71 & 235.87 & 234.46 & 0.81 \\
\hline & H89 & 223.72 & 230.02 & 227.3 & 1.81 \\
\hline \multirow[t]{6}{*}{$0655 \mathrm{~A} / 55$} & Ice Con & 99 & 100 & 99.98 & 0.13 \\
\hline & V18 & 250.19 & 254.15 & 251.95 & 0.82 \\
\hline & V36 & 247.97 & 250.18 & 249.24 & 0.53 \\
\hline & V89 & 238.51 & 244.7 & 241.72 & 1.96 \\
\hline & H18 & 232.21 & 236.09 & 234.11 & 0.82 \\
\hline & H89 & 225.65 & 233.19 & 229.27 & 2.01 \\
\hline \multirow[t]{6}{*}{$2055 \mathrm{D} / 85$} & Ice Con & 100 & 100 & 100 & 0 \\
\hline & V18 & 250.04 & 253.41 & 251.57 & 0.78 \\
\hline & V36 & 248.13 & 249.93 & 248.77 & 0.48 \\
\hline & V89 & 236.55 & 243.69 & 240.05 & 2.02 \\
\hline & H18 & 230.9 & 237.08 & 233.75 & 1.26 \\
\hline & H89 & 225.76 & 233.29 & 229.55 & 2.14 \\
\hline \multirow[t]{6}{*}{$2234 \mathrm{D} / 44$} & Ice Con & 100 & 100 & 100 & 0 \\
\hline & V18 & 250.55 & 253.18 & 251.86 & 0.64 \\
\hline & V36 & 247.83 & 250.53 & 248.61 & 0.61 \\
\hline & V89 & 236.58 & 243.99 & 239.74 & 1.84 \\
\hline & H18 & 230.8 & 235.56 & 233.97 & 1.18 \\
\hline & H89 & 225.79 & 234.46 & 229.62 & 2.26 \\
\hline
\end{tabular}


$\delta \mathrm{R}_{\text {min }}$ in regions where sea ice is generally highly consolidated such as in the high Arctic [see Fig. 2(a)]. It is thus possible that the precision value established here is underestimated. That being said, by comparing the IC standard deviations in Table II $(\leq 0.4 \%)$ with the standard deviation of the distribution of probabilities resulting from sensor noise $(2.2 \%)$, it is very likely that the NT2 precision is limited by the sensor noise.

\section{B. NT2 Algorithm Retrieval Uncertainty}

We now examine the NT2 IC retrieval uncertainties defined in Section II as the standard deviation of the IC values corresponding to the 20 smallest $\delta \mathrm{R}$. To analyze the regional and seasonal variations of the NT2 IC retrievals and corresponding uncertainties, we present daily averaged values based on averaged footprint-by-footprint swath-by-swath retrievals for the 15th of each month in 2010. Results are presented on a $12.5-\mathrm{km}$ polar stereographic grid. Due to the $3-\mathrm{dB}$ footprint size, IC retrievals along the coast require land-to-ocean spillover correction (see for instance [3, Sec. 4.2]). Radiometric properties of ice-free oceans with high cloud liquid water content lead to ambiguity in the IC retrievals. To eliminate these weather effects over ice-free ocean, weather filters based on the spectral GR are usually used [2], [21]. IC retrievals presented here were calculated without land spillover correction, and AMSR-E Level 3 TB were used to eliminate the weather effects over ice-free ocean. The daily gridded IC and its associated uncertainty are presented for the Northern Hemisphere in Figs. 5 and 6 and for the Southern Hemisphere in Figs. 7 and 8. Since, the seasonal, regional, and interannual variabilities of IC and extent have been extensively studied using more than three decades of passive microwave satellite observations [22]-[24], this paper focuses on the NT2 algorithm uncertainty values (and the daily IC variability in Section III-D).

Figs. 5 and 6 shows the typical seasonal variation of the Arctic sea ice cover that reaches a maximum extent in March, and a minimum extent in September. Beginning in June and extending through the months of July, August, and September, there are large areas of the central Arctic that have reduced ICs. In October, there is an increase in the extent of the sea ice cover, and this increase continues until the following March. The daily averaged IC retrieval uncertainty maps (see Fig. 5 and 6) corresponding to each of the IC maps show that, from January through June, the central Arctic has a broad range of retrieval uncertainties $(0.4 \%-3.8 \%)$, whereas the MIZ systematically has the largest uncertainties (up to 5\%). With the beginning of the melting period, there are larger areas of greater uncertainty often, but not always, corresponding to the areas of reduced ICs. The relationship between NT2 IC uncertainty and ice type is discussed in Section III-C. The NT2 IC uncertainties remain high until October, when a consolidated ice cover is formed. Locally, areas of lower IC uncertainties exist and correspond to $100 \% \mathrm{IC}$.

Figs. 7 and 8 shows the daily IC and corresponding retrieval uncertainty maps for the Antarctic for the 15th of each month in 2010. In the Southern Hemisphere, the month of minimum sea ice extent is February, whereas the month of maximum extent is October. In general, the Antarctic sea ice cover exhibits faster seasonal IC variations than those in the Northern Hemisphere. Over Antarctic sea ice, the areas of high retrieval uncertainty are mostly found in the MIZ (e.g., on December 15, 2010 in the Ross and Amundsen seas where uncertainties of up to $7 \%$ are possible [see Fig. 8(a)]). During winter, IC uncertainties in the interior pack generally appear smaller in the Southern Hemisphere than the Northern Hemisphere. Although, as in the Arctic, areas of high retrieval uncertainty can be found in areas of lower IC in the interior ice pack [see Figs. 7 and 8]. For instance, in the interior pack of the Weddell Sea on June 15, 2010 [see Fig. 7(a)] IC uncertainties of up to $3.5 \%$ are centered over an area of $90 \%-99 \%$ IC.

There are several reasons for the more extensive areas of higher retrieval uncertainty during the summer months in both hemispheres. The properties of the summer sea ice cover are more complex than in winter. The sea ice snow cover very likely has undergone several freeze-melt cycles creating ice layers. In the Arctic, the snow cover can completely melt, and either drain into the ocean or contribute to the formation of melt ponds. In the Antarctic, sea ice itself may have been flooded. Finally, the atmospheric contribution to retrieval uncertainties is greater during summer because of lower sea ice emissivities, and greater atmospheric water vapor and cloud liquid water content.

\section{Relationship Between IC Uncertainty and NT2 Ice Types}

We now show an association between retrieval uncertainty and specific NT2 sea ice types, namely, FY/MY ice, ice type $\mathrm{C} /$ deep snow, and ice type $\mathrm{C} /$ new ice. Based on published NT2 IC validation studies, there is an association between retrieval accuracy and these ice types. For example, a comparison of IC derived from Aqua/AMSR-E and Landsat 7/ETM + imagery obtained in March 2003 showed good overall agreement with AMSR-E minus Landsat IC of $\sim 1 \%$ for areas of young and first-year ice [4]. However, for all ice types combined and for the full range of ICs, the difference ranged from $0 \%$ to $3 \%$, and the RMSE ranged from $1 \%$ to $8 \%$, depending on the region. For first-year ice in the Chukchi Sea, an IC difference of less than $1 \%$ and an RMSE of $1.6 \%$ were obtained. In [4], negative difference (i.e., higher Landsat IC than AMSR-E) of $\sim 5 \%$ in areas of new ice production with an associated RMSE of $8 \%$ was also found. Finally, in [4], areas of deep snow in the Bering Sea resulted in an underestimate $(\sim 10 \%)$ of IC. While a direct comparison of these validation results and the NT2 IC relative uncertainties cannot be made at this point, we note that, at a similar time of the year in 2010, the NT2 IC relative uncertainties over ice in the Chukchi Sea is $0.5 \%$ (see Table III). The NT2 IC uncertainties found in the St. Lawrence Island and Anadyr Strait polynyas is $2 \%$ (see Table III).

Fig. 9 shows the IC and uncertainty for March 15 in the Northern Hemisphere, and the ice type C/deep snow and ice type $\mathrm{C} /$ new IC. Visually, it is apparent that there is a relationship between the NT2 IC uncertainty and the presence of ice type C. The linear correlation $\left(r^{2}=0.87\right)$ is the strongest for ice type $\mathrm{C} /$ deep snow IC, where its concentration is less than $30 \%$ [see Fig. 10(a)]. Using the 15 th day of each month in $2010, r^{2}$ values are higher than 0.85 during the winter dates, higher than 0.70 during the spring and fall, but was only 0.31 on August 15 . The 


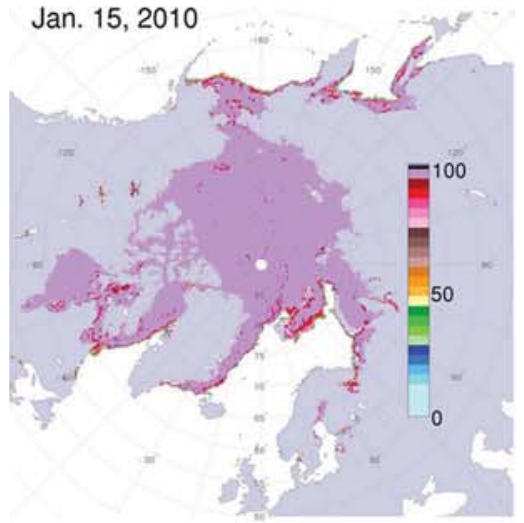

(a)

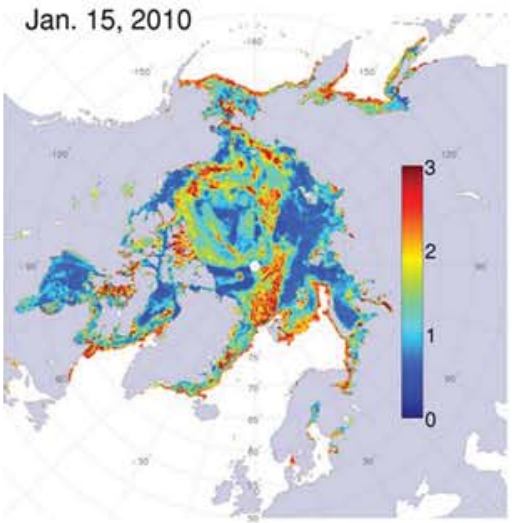

(d)

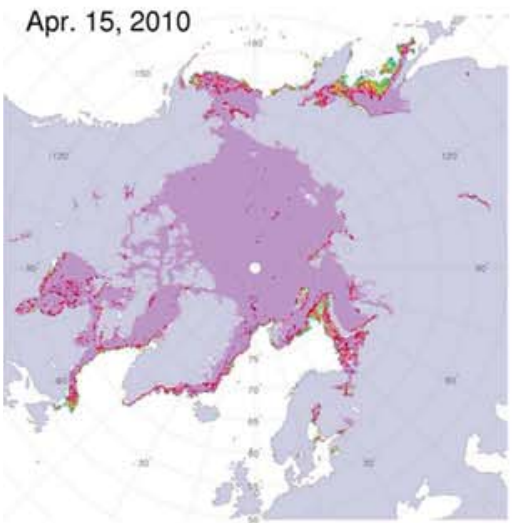

(g)

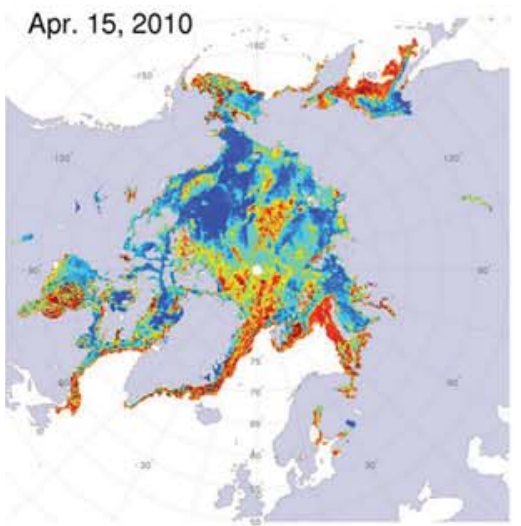

(j)

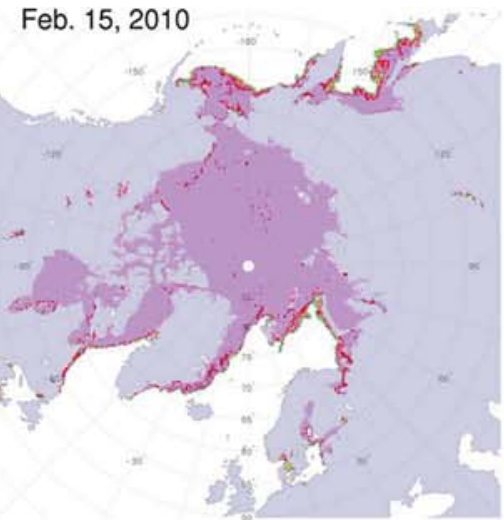

(b)

Feb. 15, 2010

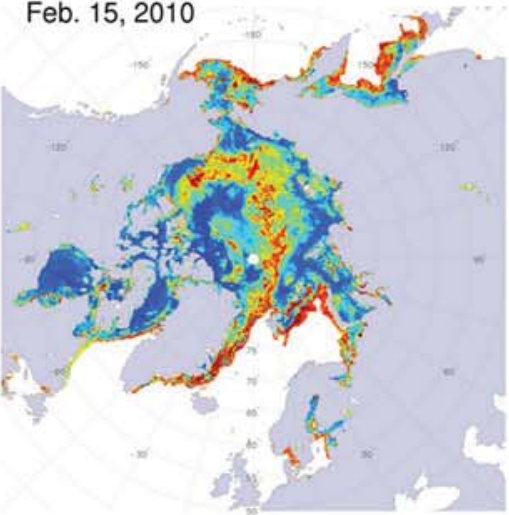

(e)

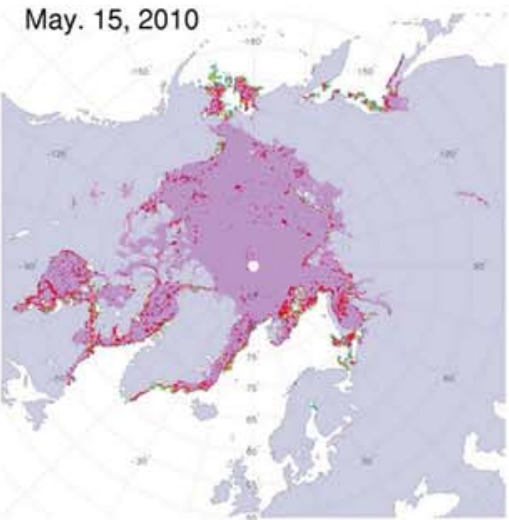

(h)

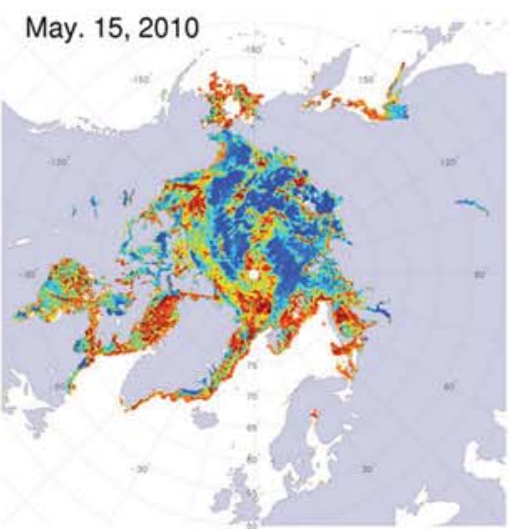

(k)

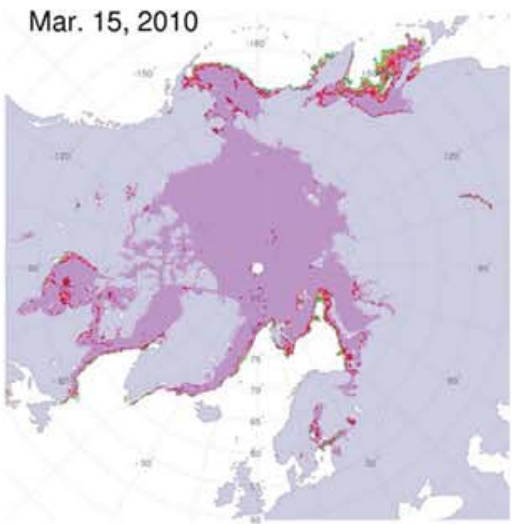

(c)

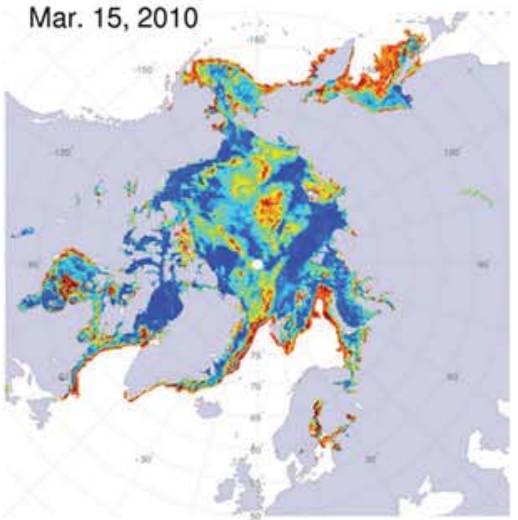

(f)

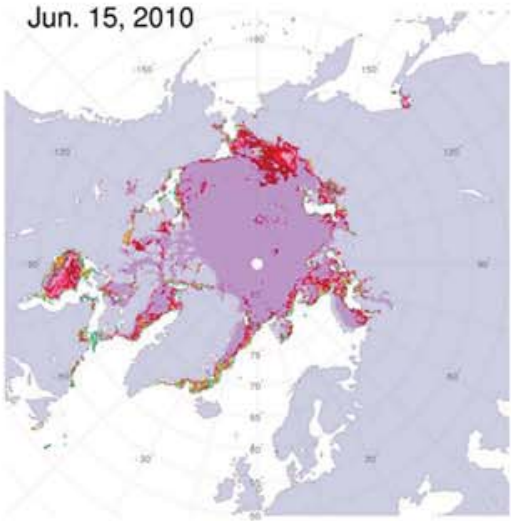

(i)

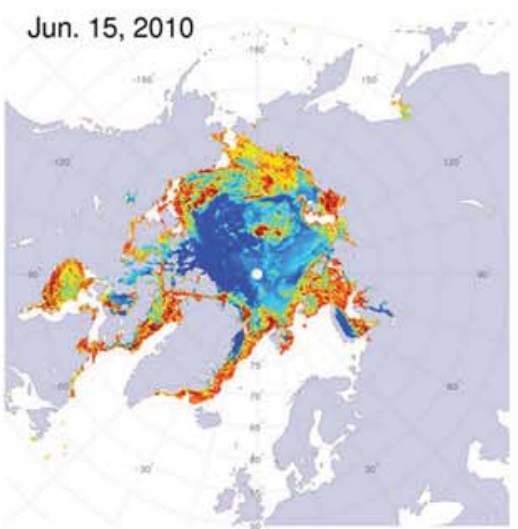

(1)

Fig. 5. Daily averaged IC (a)-(c), (g)-(i) and retrieval uncertainty (d)-(f), (j)-(1) for the 15 th of each month from January through June 2010 in the Northern Hemisphere. Both quantities are expressed in percentage. 


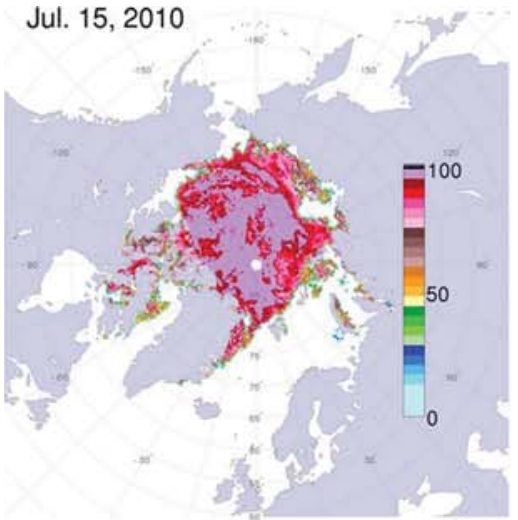

(a)

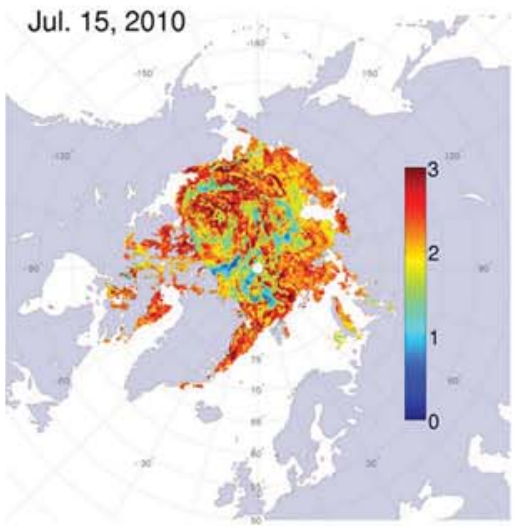

(d)

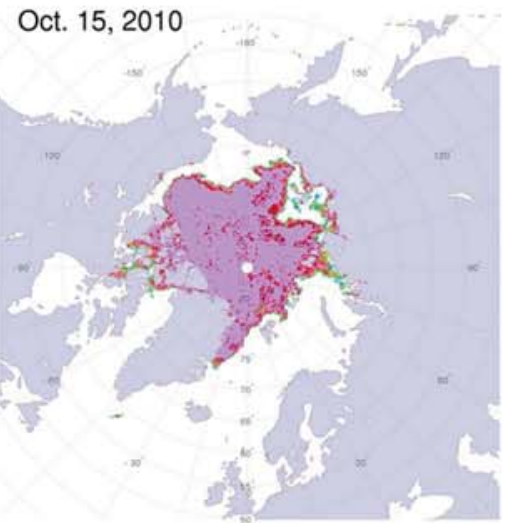

(g)

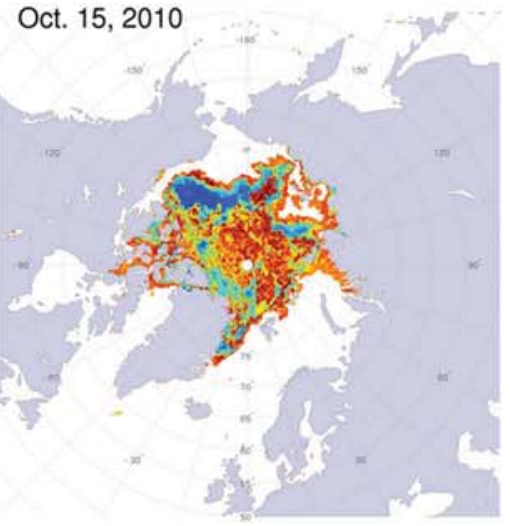

(j)

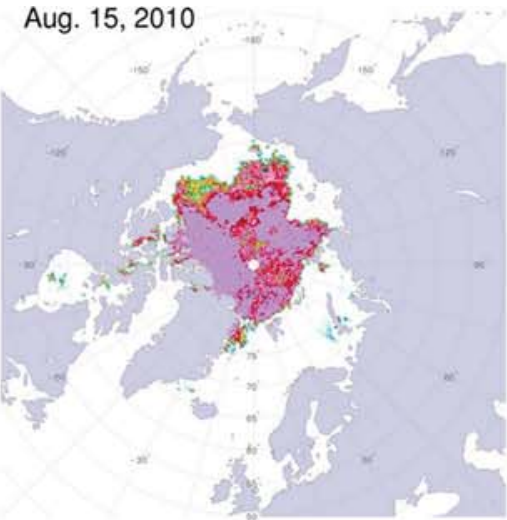

(b)

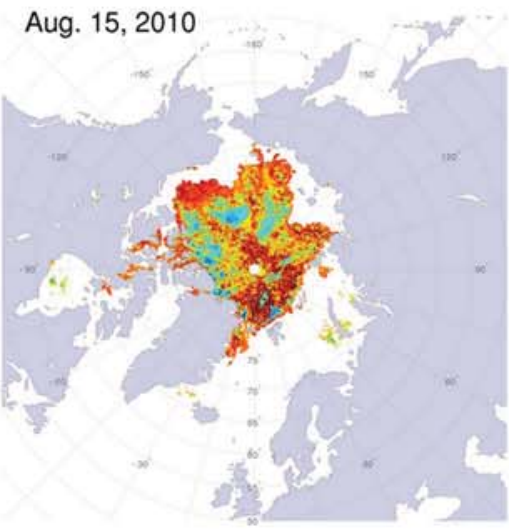

(e)

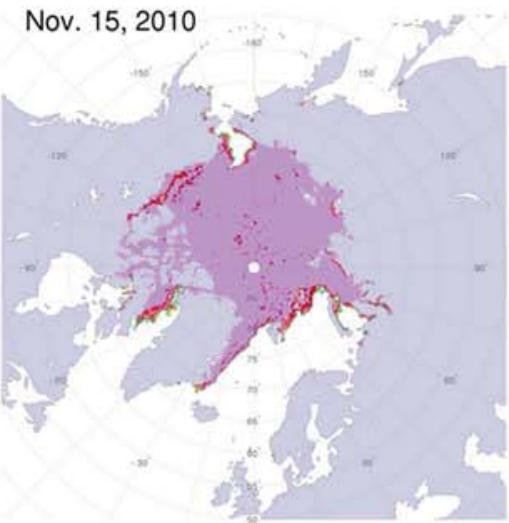

(h)

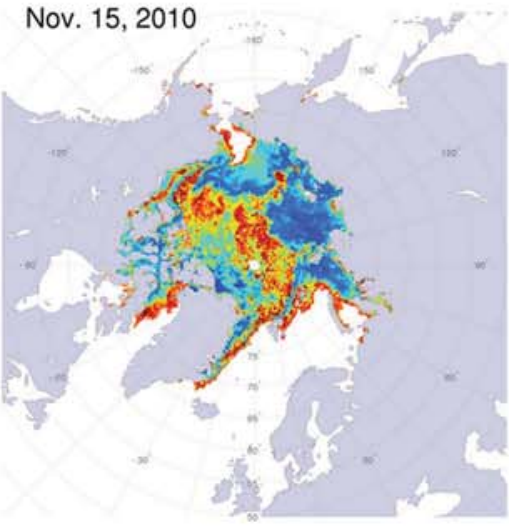

(k)

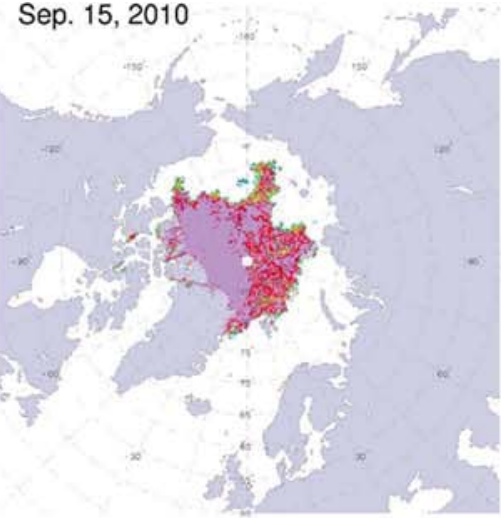

(c)

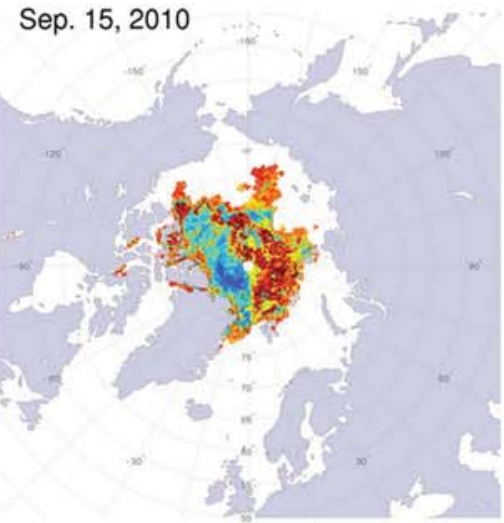

(f)

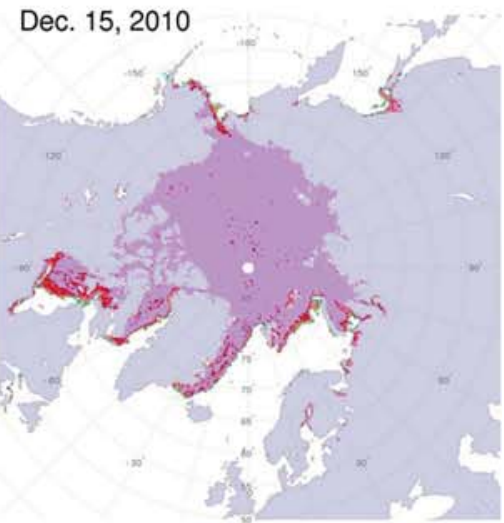

(i)

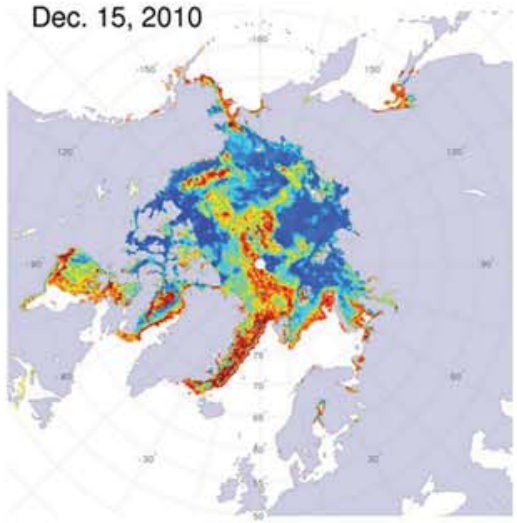

(1)

Fig. 6. Same as Fig. 5 from July through December 2010. 
Jan. 15,2010

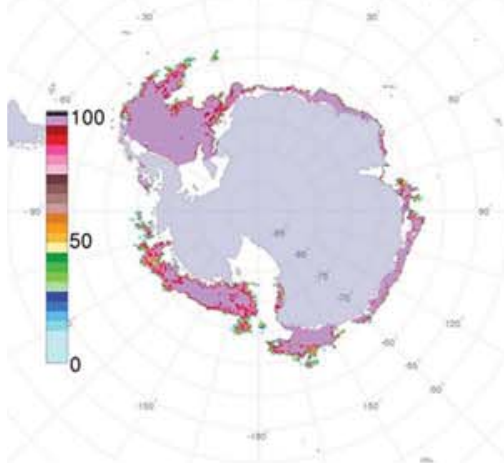

(a)

Jan. 15, 2010

(d)

Apr. 15, 2010

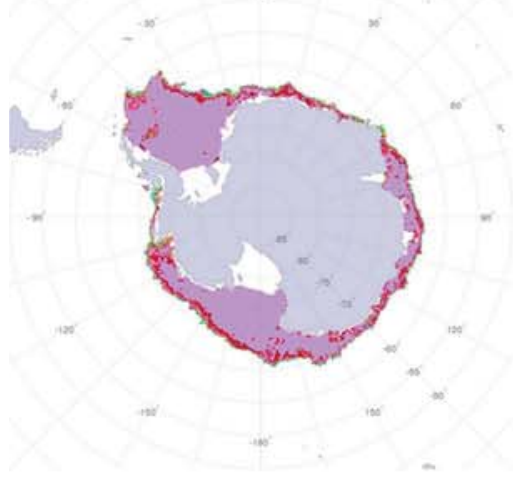

(g)

Apr. 15, 2010

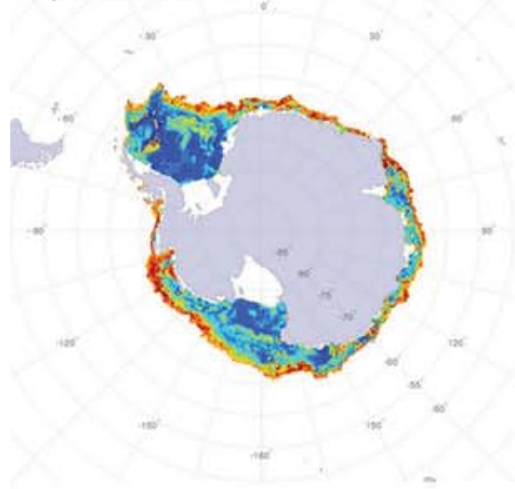

(j)
Feb. 15, 2010

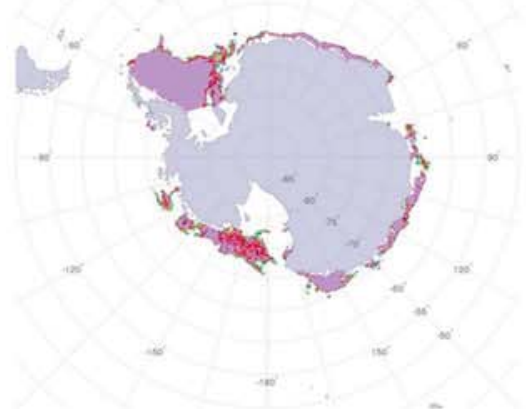

(b)

Feb. 15, 2010

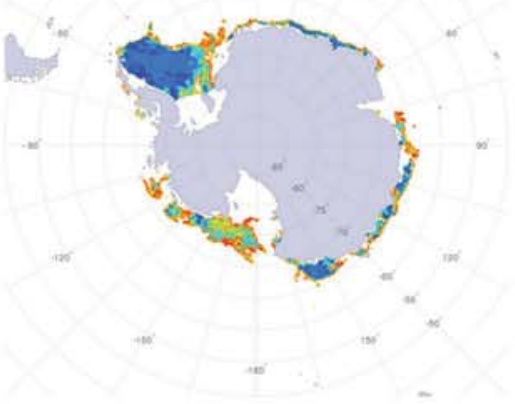

(e)

May. 15, 2010

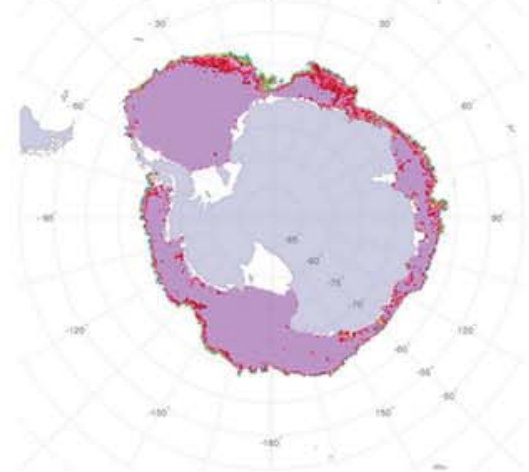

(h)

May. 15, 2010

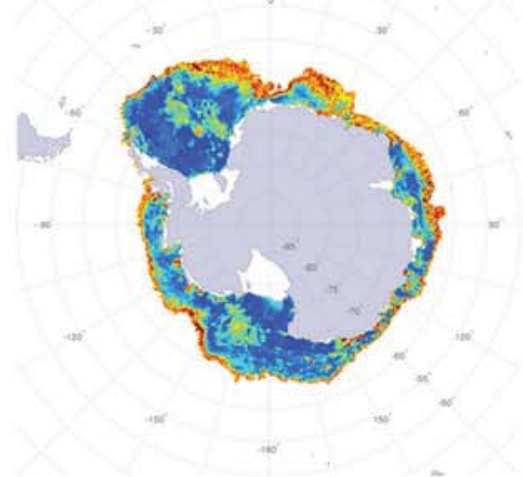

(k)
Mar. 15, 2010

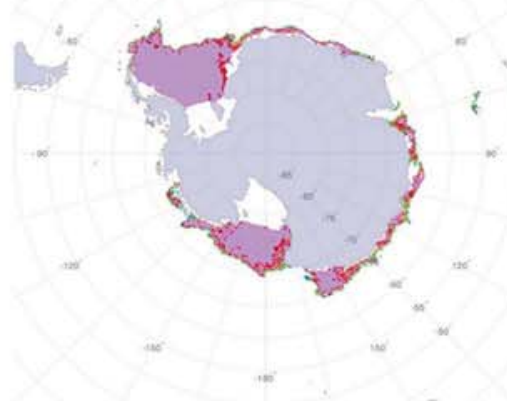

(c)

Mar. 15, 2010

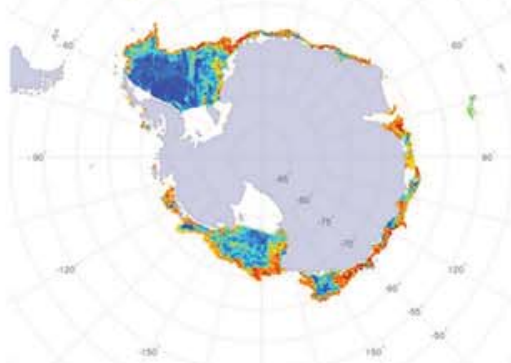

(f)

Jun. 15, 2010

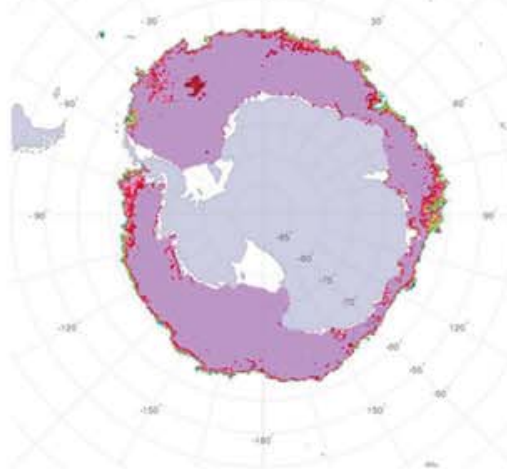

(i)

Jun. 15, 2010

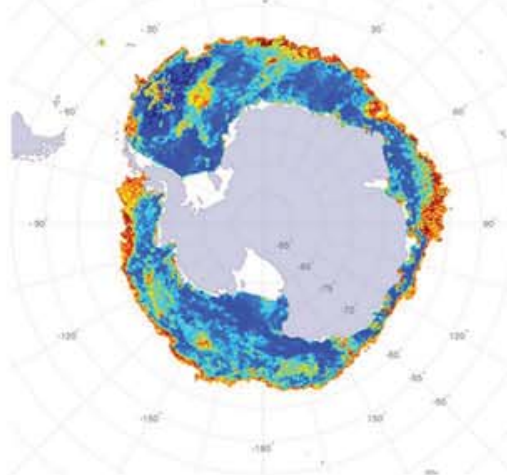

(1)

Fig. 7. Same as Fig. 5 for the Southern Hemisphere. Ice shelves are in white, similarly to open water areas. 
Jul. 15, 2010

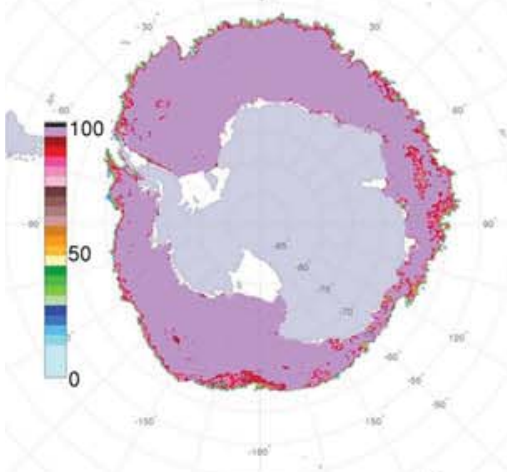

(a)

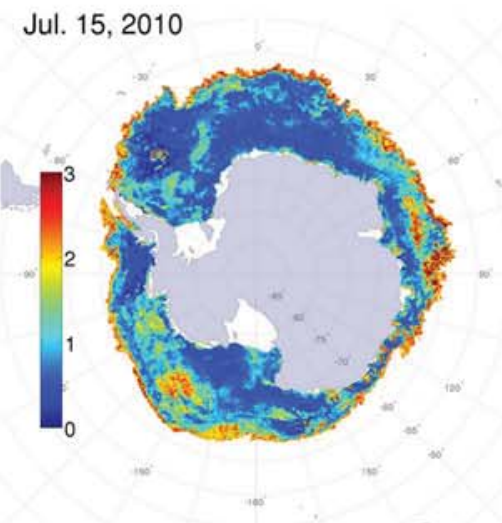

(d)

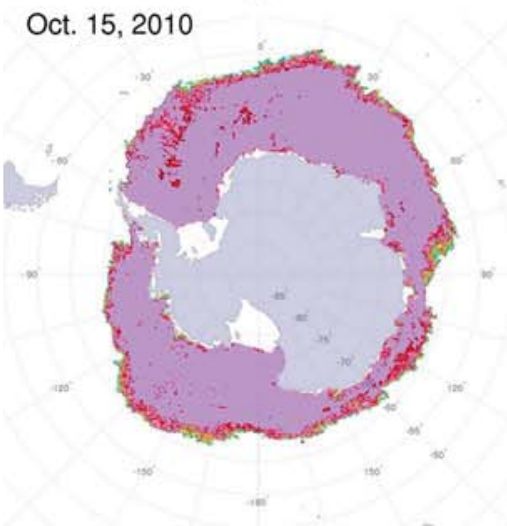

(g)

Oct. 15,2010

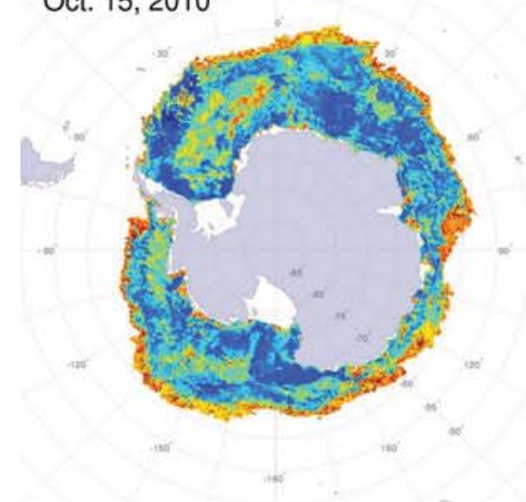

(j)
Aug. 15, 2010

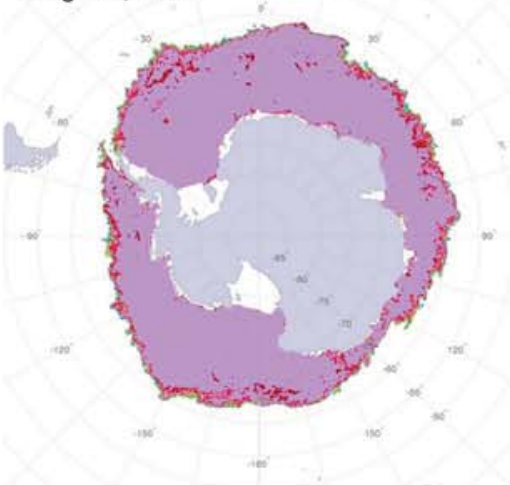

(b)

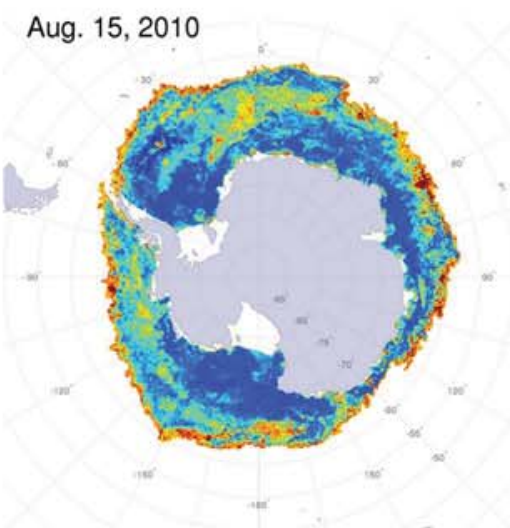

(e)

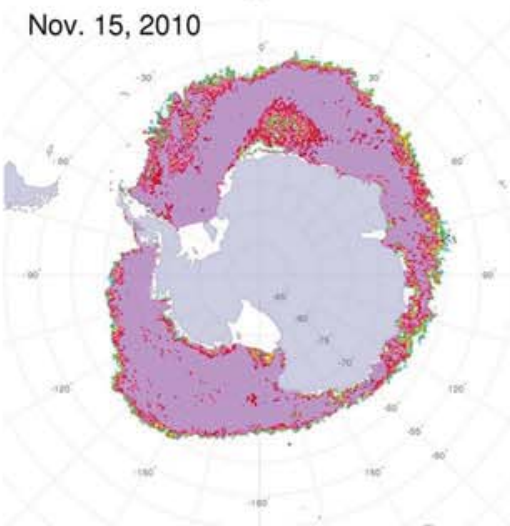

(h)

Nov. 15,2010

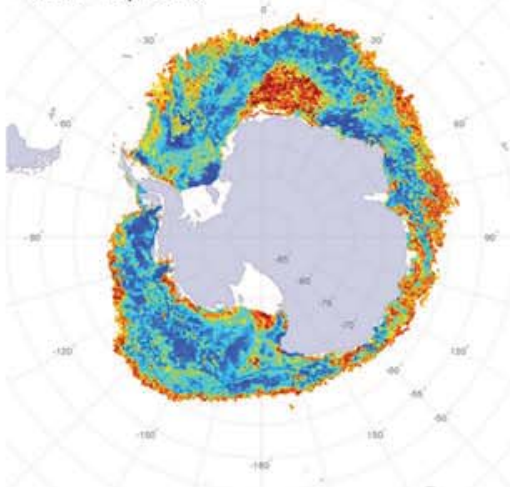

(k)
Sep. 15,2010

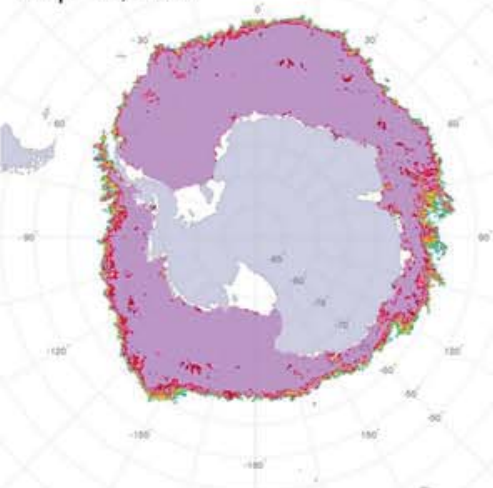

(c)

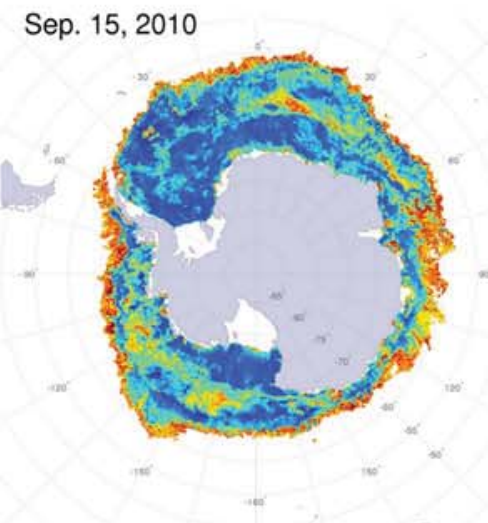

(f)

Dec. 15, 2010

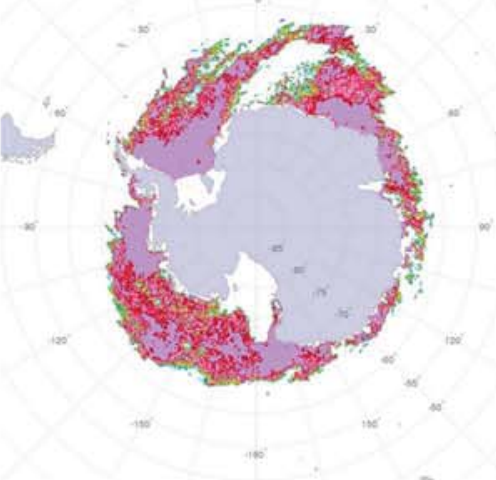

(i)

Dec. 15,2010

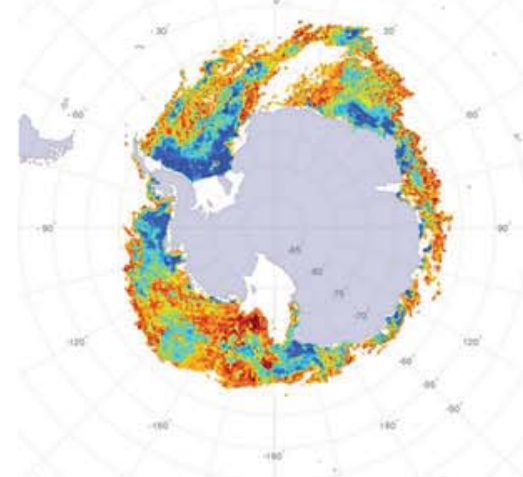

(1)

Fig. 8. Same as Fig. 7 from July through December 2010. 
TABLE III

AVERAGE IC AND IC UNCERTAINTY IN Four SELECTED AREAS IN THE ARCTIC ON MARCH 15, 2010

\begin{tabular}{ccc}
\hline Region & IC & Uncertainty \\
Chukchi Sea & $100.0 \% \pm 0.0 \%$ & $0.5 \% \pm 0.1 \%$ \\
St. Lawrence Island Polynya & $97.2 \% \pm 2.4 \%$ & $2.1 \% \pm 0.7 \%$ \\
Anadyr Strait & $95.2 \% \pm 4.0 \%$ & $2.1 \% \pm 0.5 \%$ \\
Fram Strait & $97.2 \% \pm 1.3 \%$ & $2.4 \% \pm 0.6 \%$ \\
\hline
\end{tabular}

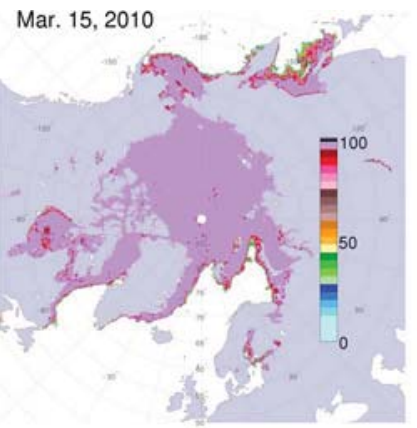

(a)

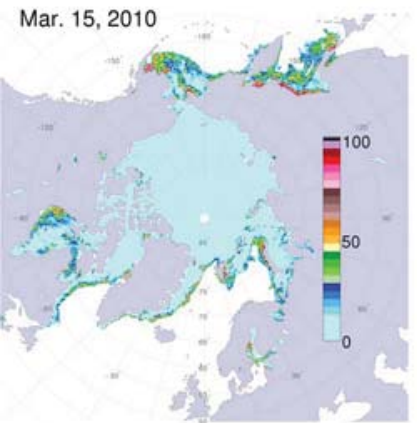

(c)

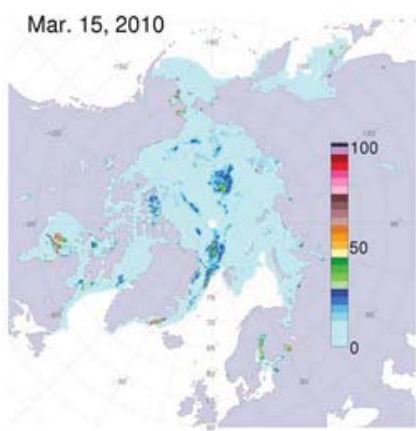

(b)

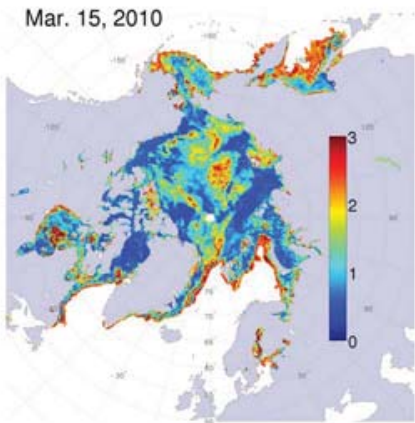

(d)
Fig. 9. Daily (a) IC, (b) ice type C/deep snow concentration, (c) ice type C/ new IC, and (d) IC retrieval uncertainty in the Northern Hemisphere for March 15, 2010.

apparent association between the NT2 IC retrieval uncertainty and ice type C/deep snow may in fact result from unresolved sea ice conditions, which appear as ice type C/deep snow high IC. Although the presence of ice type C/new ice is spatially correlated with IC uncertainties, there is no linear correlation between their values [see Fig. 10(b)]; however, a correlation between retrieval uncertainty and total IC exists. In the Southern Hemisphere, a relationship between the NT2 IC uncertainty and the presence of ice type C (see Fig. 11, for the month of September) is not as obvious as in the Northern Hemisphere.

The correlation identified in the Northern Hemisphere between the NT2 IC uncertainty and the presence of ice type C illustrates the difficulties of identifying any single source of IC uncertainty. Further work is needed to evaluate the sources of uncertainty by ice types, regions, and seasons.

\section{Daily Variability}

One of the daily averaged gridded (level 3) sea ice products archived at NSIDC is the daily AMSR-E NT2 IC. This product contains the mean daily IC at grid resolutions of 12.5 and $25 \mathrm{~km}$. The daily IC results from an average of all the IC retrievals within a given grid cell. Since a given grid cell may

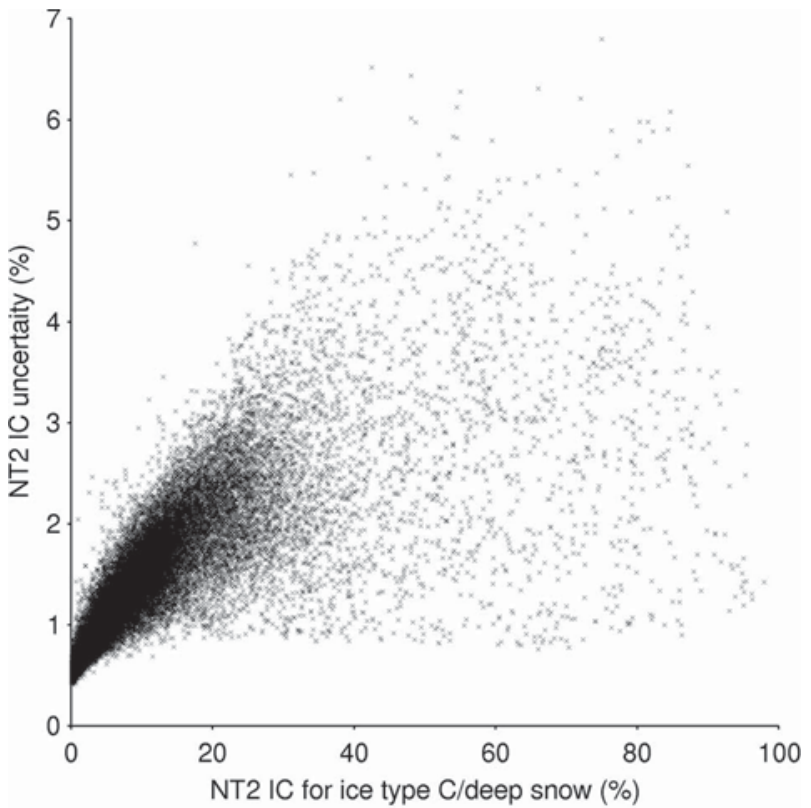

(a)

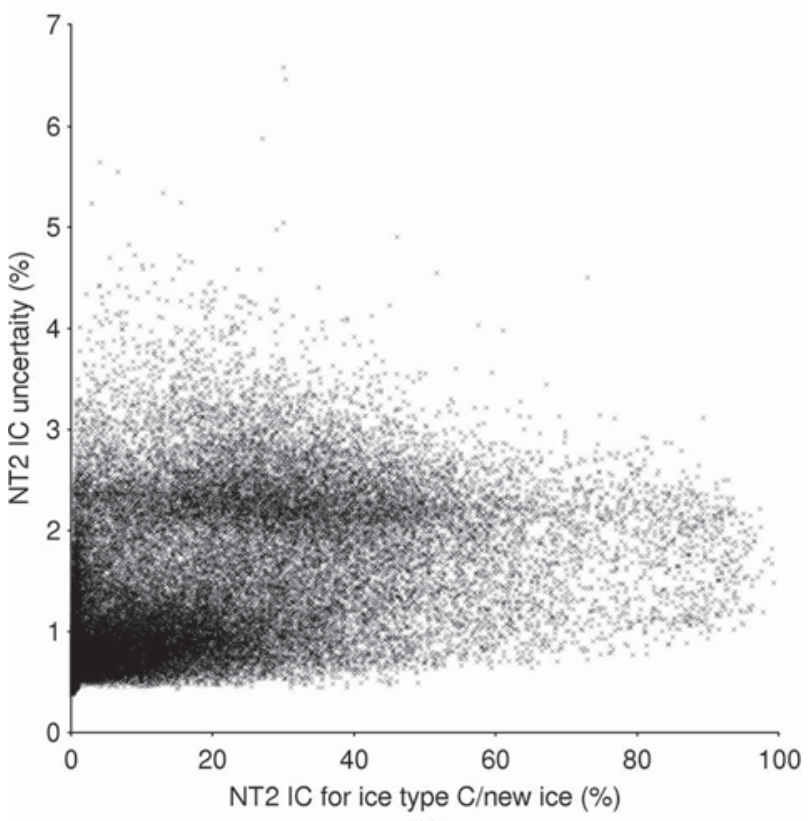

(b)

Fig. 10. Scatterplot of the NT2 IC uncertainty as a function of the NT2 IC for the retrievals on March 15, 2010 in the Northern Hemisphere where grid cells have (a) NT2 ice type C/deep snow and (b) NT2 ice type C/new ice.

contain several footprint observations per swath, and several swaths per day, all of these observations/retrievals are used to compute the daily average. Of note, the number of observations/retrievals per grid cell is neither uniform nor constant (see Fig. 12). It depends on the orbit of the day, and typically ranges from 5 to 34 for each $12.5-\mathrm{km}$ grid cell. Therefore, daily variability values based on a small number of footprints should be used with caution.

Here, we examine daily IC variabilities by calculating the standard deviations of the retrieved ICs for each $12.5-\mathrm{km}$ grid cell for the 15th of each month through 2010. The results are shown in Figs. 13 and 14 for the Northern and Southern Hemisphere, respectively. 


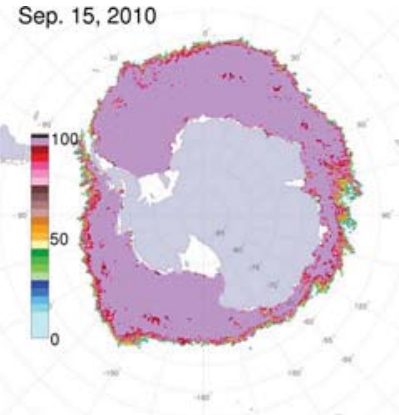

(a)

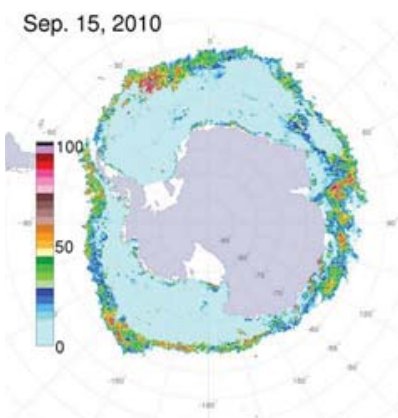

(c)

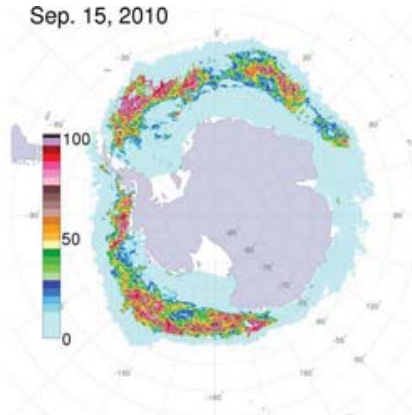

(b)

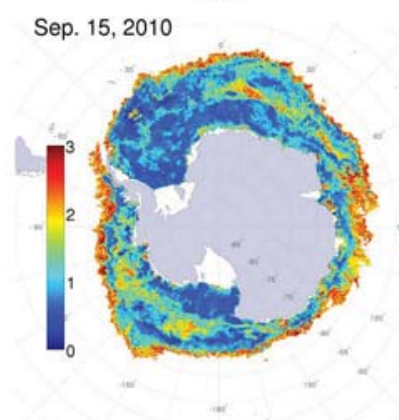

(d)
Fig. 11. Daily (a) IC, (b) ice type C/deep snow concentration, (c) ice type C/ new IC, and (d) IC retrieval uncertainty in the Southern Hemisphere for September 15, 2010.

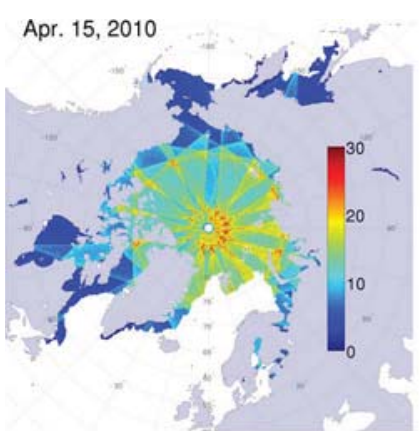

(a)

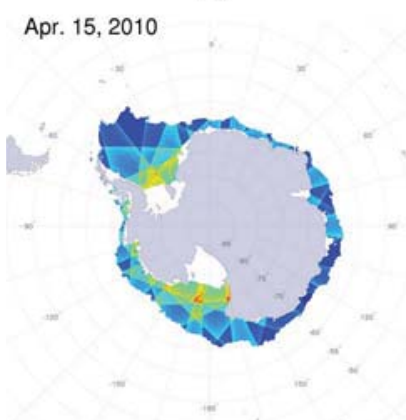

(c)

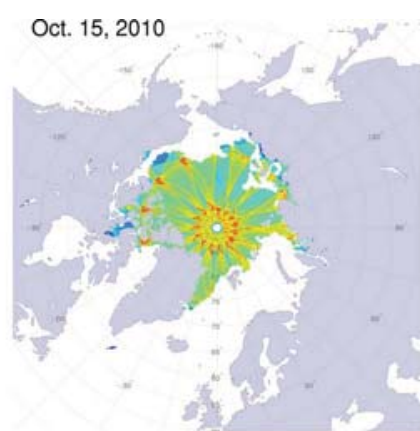

(b)

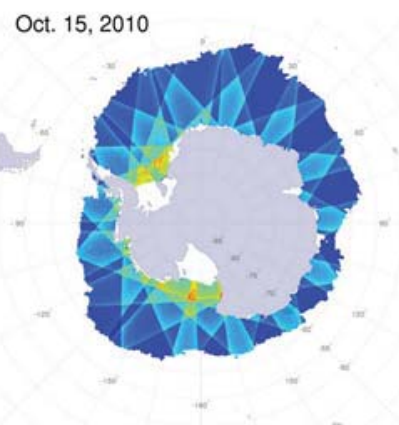

(d)
Fig. 12. Number of NT2 IC retrievals (i.e., of AMSR-E footprint observations where sea ice is present) per $12.5-\mathrm{km}$ grid cell of the polar stereographic grid for (a) and (c) April 15 and (b) and (d) October 15 in the Northern and Southern Hemispheres.

In the Northern Hemisphere, most of the daily variability is found in the MIZs (see Fig. 13), which are areas more likely subject to subdaily forcing by atmosphere and ocean. During the winter months, the central Arctic exhibits a weak daily IC variability $(0 \%-4 \%)$. In contrast, values up to $\sim 10 \%$ can exist in summer in the interior ice pack. Beginning in June, there are larger areas of greater daily variability as a result of a number of factors, including divergence and convergence of sea ice, diurnal freeze-thaw cycles, and the formation of melt ponds. The latter two change the microwave emissivity of the sea ice cover.

The extent of high daily IC variability (often up to $20 \%$, locally $30 \%$ ) matches the extent of the MIZ, with larger areas in summer than winter. Large areas of variability are also seen at the start of freeze-up in October, which may result from the rapid formation of sea ice from nilas to new ice and thicker ice types, all with different microwave emissivities, and from the greater atmospheric contribution over low emissive new and thin ice. Other areas having large daily variability $(5 \%-15 \%)$ in winter are coastal polynyas driven by winds. The cycle of polynyas opening by wind forcing and then the rapid refreeze of the polynya results in large daily variations of IC. This is clearly visible in the coastal polynyas in the Bering Sea, and in the North Water polynya (which lies along the northern Greenland coast in Baffin Bay).

The IC daily variability for the Southern Hemisphere (see Fig. 14) exhibits similar patterns, with high daily variability in the MIZ year round, and increased variability during the summer months. The extent of areas with high daily variability in summer is significantly larger than in the Northern Hemisphere primarily because the Southern Ocean ice cover is more divergent and, on average, thinner and hence more dynamic than in the Arctic. Although as in the Arctic, coastal polynyas exhibit large IC daily variability (up to $15 \%$ ). The largest recurring polynya in the Antarctic is the Ross Sea polynya, visible during spring months (September-November, Fig. 14). Many other smaller polynyas are observed along the East Antarctic coast where glacier tongues are positioned perpendicular to the prevailing circumpolar winds. The very large areas of daily variability observed for November and December probably result from the fact that the ice cover breakup, unlike the Arctic, occurs more rapidly over vast areas (see corresponding IC maps shown in Figs. 5 and 6). Moreover, weather effects are in general more frequent than in the Arctic throughout the year. Flooding of sea ice and snow-ice formation are more common in the Antarctic. These processes change emissivities within a day and thus lead to variability using the NT2 algorithm. Another weather effect is the frequent change between convergent and divergent conditions, which causes frequent IC changes. However, using the NT2 IC algorithm, the average daily IC changes due to this effect were less than $\sim 3 \%$ in 2010 (see Fig. 14).

Finally, we compare the range of the daily IC variability with the range of the NT2 IC uncertainty. The daily IC variability values are of the same range as the IC uncertainty in winter [see Fig. 15(a)], but are larger than that in summer [see Fig. 15(b)]. The daily IC variability may range up to $6 \%$ (15\%) in January (July), whereas the IC retrieval uncertainties are not higher than $\sim 4 \%-5 \%$ during these months.

\section{CONCLUSION}

The NT2 IC retrievals are widely used in cryospheric research, in model assessment, and for marine and offshore 


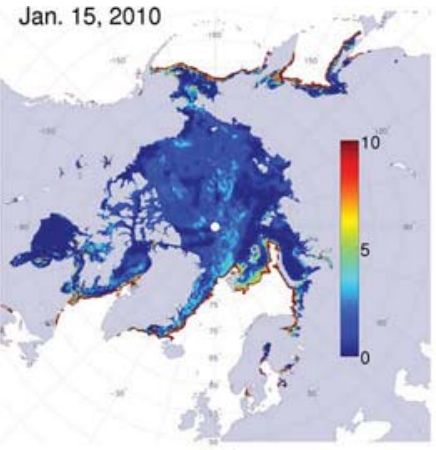

(a)

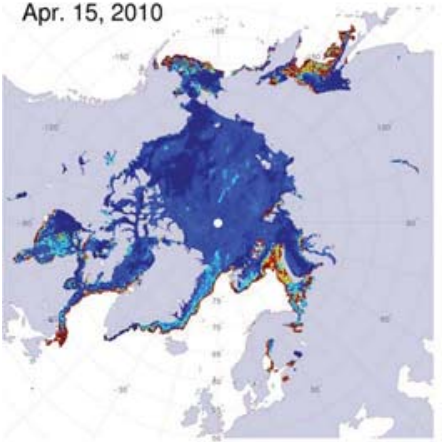

(d)

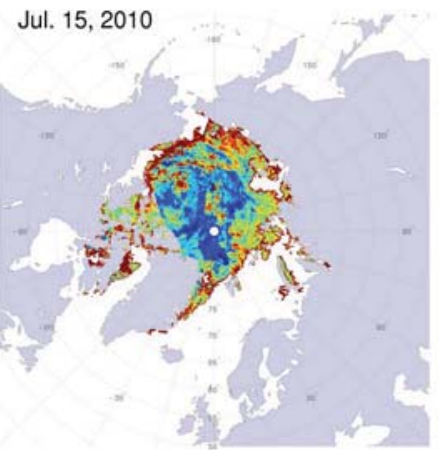

(g)

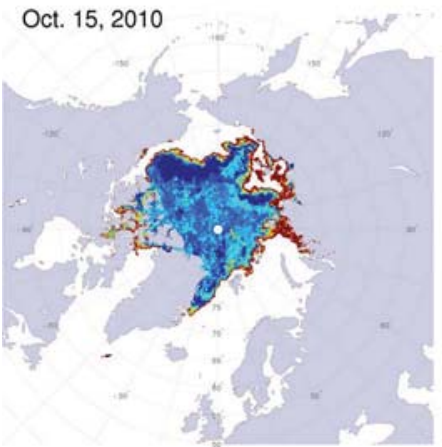

(j)

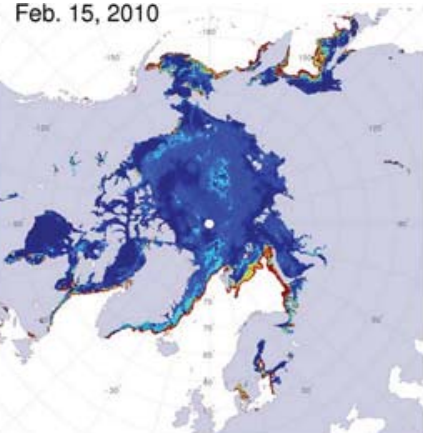

(b)

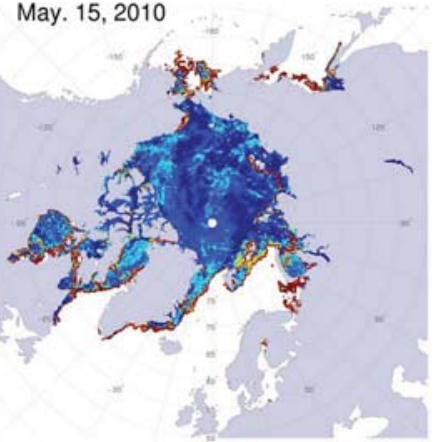

(e)

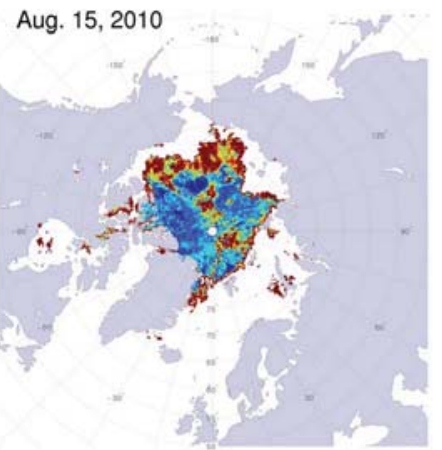

(h)

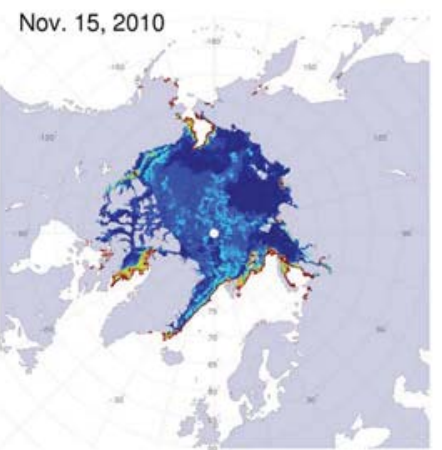

(k)

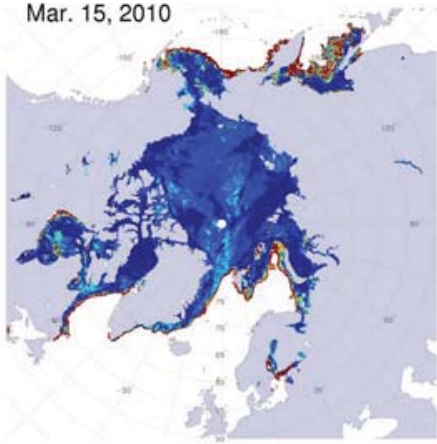

(c)

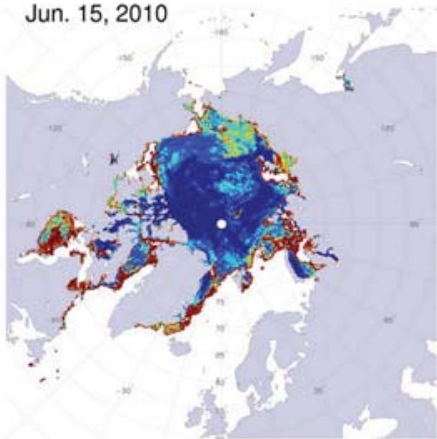

(f)

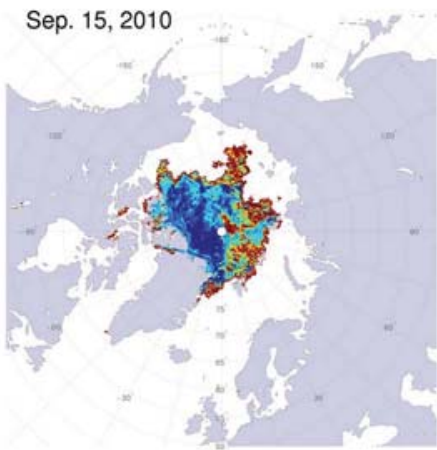

(i)

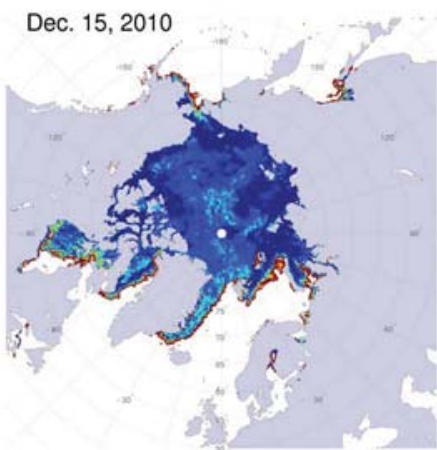

(1)

Fig. 13. Daily IC variability (in percentage) in the Northern Hemisphere retrieved for each grid cell for the 15 th of each month for 2010.

activities. To further extend the utility of the NT2 IC retrievals, and to respond to a need for satellite retrieval uncertainties, we have proposed a method to estimate the associated NT2 relative IC uncertainty. Uncertainty estimates are critically needed to assess accurately global and regional trends, to quantify heat flux and sea ice volume, and to improve sea ice data assimilation by providing spatial distributions of uncertainties. In addition, we presented maps of daily IC variability based on all footprint ob- servations within each $12.5-\mathrm{km}$ grid cell. Both the retrieved uncertainty and daily variability are important when assessing the satellite IC product with in situ, shipborne and airborne observations. Knowledge about daily IC variability is also extremely important for off-shore and marine activities, particularly as Arctic sea ice becomes thinner, and is thus more dynamic.

With the proposed approach, NT2 IC and uncertainty can be retrieved simultaneously. A similar statistical approach may be 


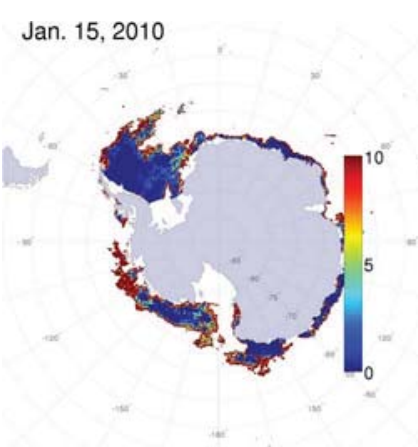

(a)

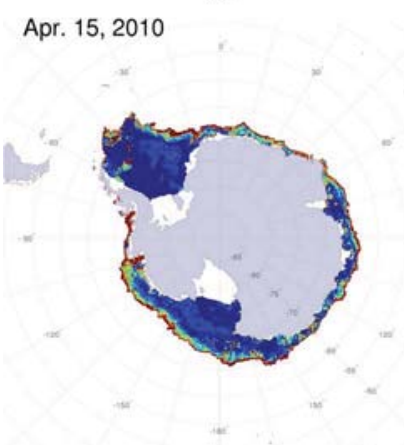

(d)

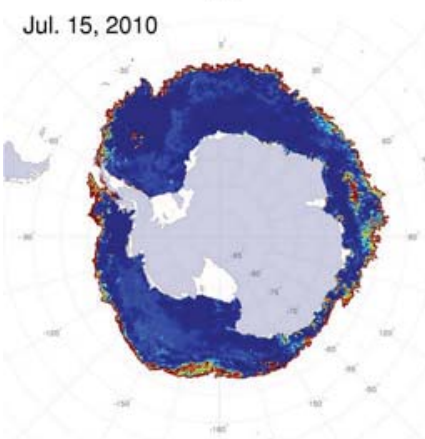

(g)

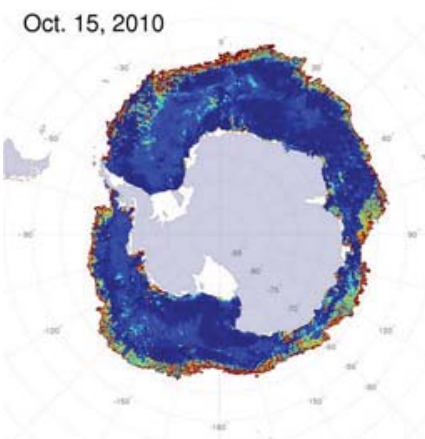

(j)

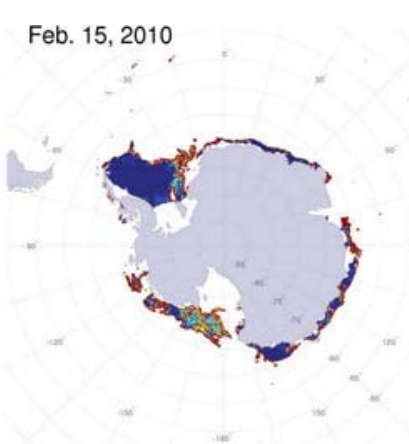

(b)

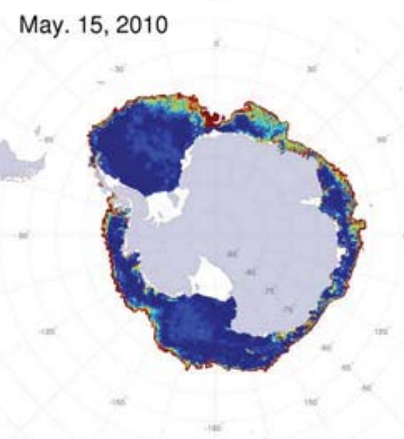

(e)

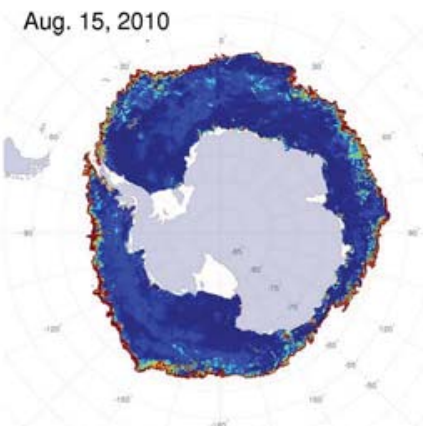

(h)

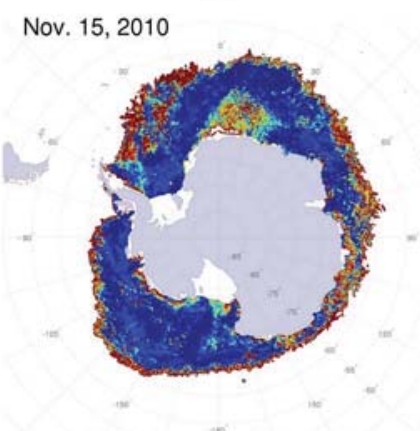

(k)

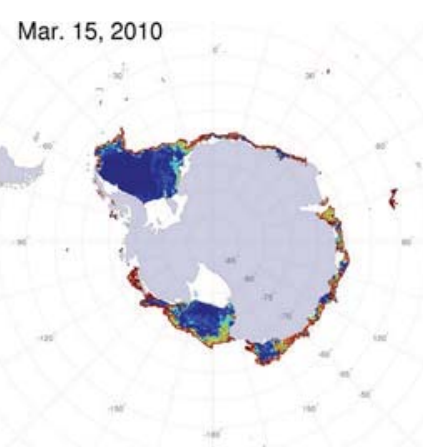

(c)

Jun. 15, 2010

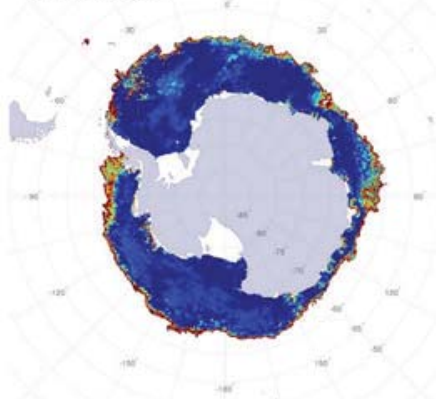

(f)

Sep. 15,2010

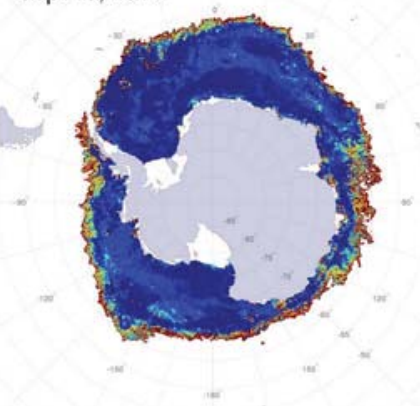

(i)

Dec. 15,2010

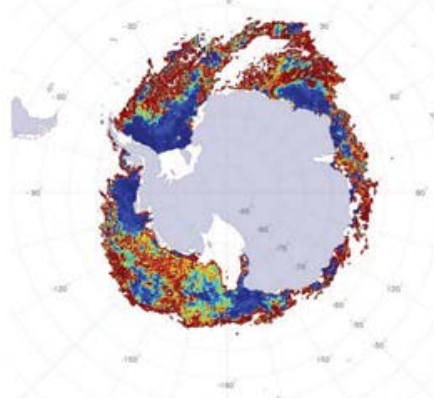

(1)

Fig. 14. Same as Fig. 13 for the Southern Hemisphere. Ice shelves are in white, similarly to open water areas.

applied to other IC algorithms using a minimization procedure. The retrieval uncertainty estimate is defined as the standard deviation of the IC solutions corresponding to the 20 smallest $\delta \mathrm{R}_{s}$. The same definition is used for all footprint observations, which enables easy spatial and temporal comparisons in both hemispheres. In this paper, we have presented the regional and seasonal variations in the NT2 ICs, retrieval uncertainties, and daily variabilities for both hemispheres for the 15 th of each month in 2010 at a spatial resolution of $12.5 \mathrm{~km}$.

The uncertainties presented here are not absolute and still need to be calibrated with independent sources of sea ICs. Previous validation studies have been carried out to provide a measure of retrieval accuracy but over very limited areas and times. These same validation data sets may be also used to 


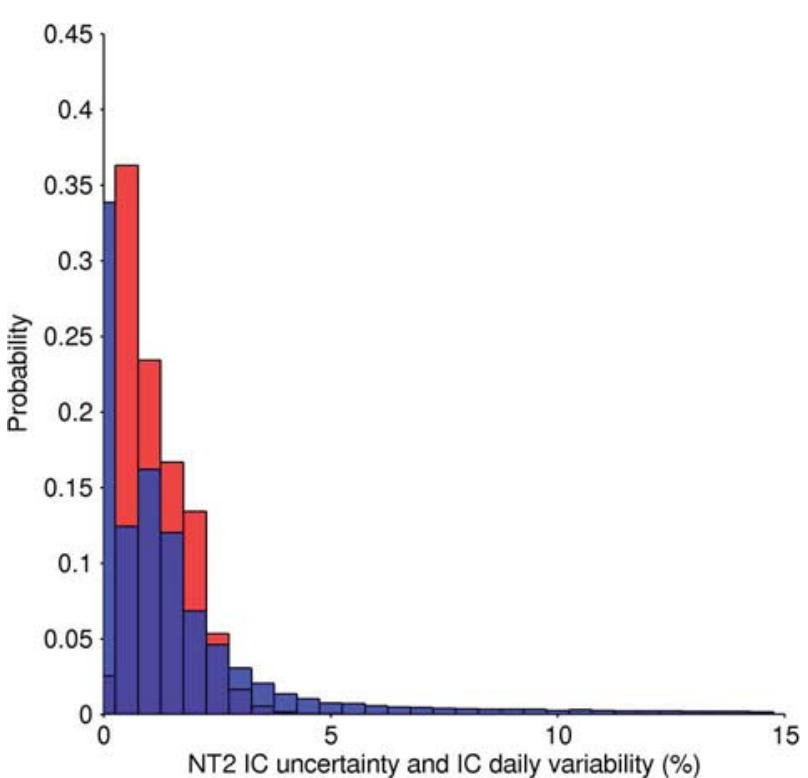

(a)

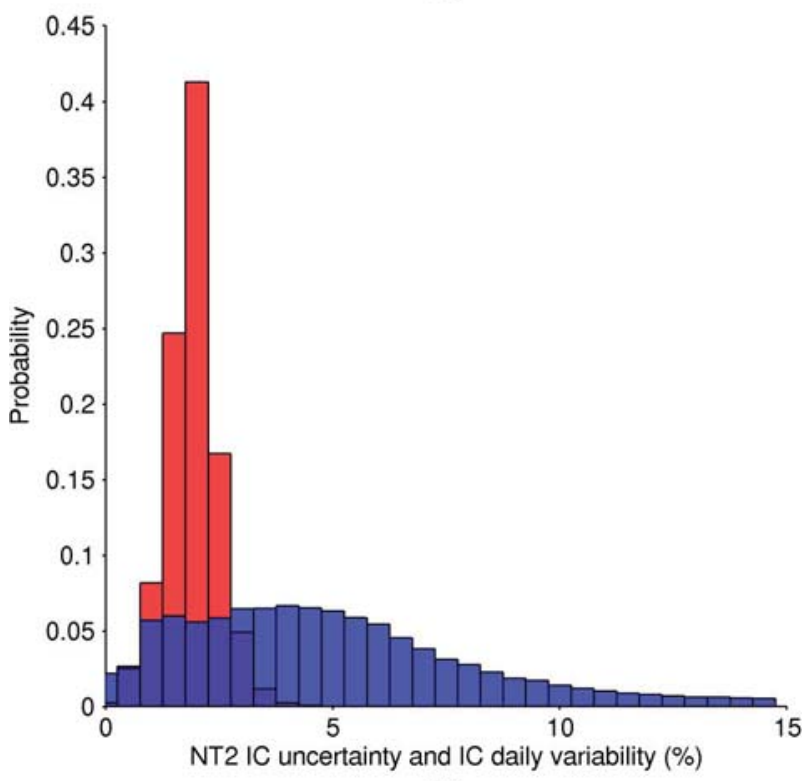

(b)

Fig. 15. Probability of occurrence of daily IC uncertainty (red) and variability (blue) in the Northern Hemisphere for January 15, 2010 and July 15, 2010.

calibrate the uncertainties defined in this paper, thereby potentially providing a quantitative measure of retrieval uncertainty over a much greater spatial and temporal range. It may also be possible to calibrate the relative uncertainty defined in this paper by using new validation data sets (e.g., from Visible Infrared Imager Radiometer Suite (VIIRS) and commercial very high spatial resolution data from WorldView-2, GeoEye-1).

Based on daily retrieval uncertainty maps for the 15 th of each month in 2010 and for both Northern and Southern Hemispheres, we found that the NT2 IC retrieval uncertainties are: 1) higher in areas of new ice production (e.g., in MIZs, and coastal polynyas); 2) higher in areas where ice type $\mathrm{C}$ is present; and 3) higher at the onset of melting and during the melting season. Thus, larger uncertainties exist in summer than in winter. The uncertainty was strongly correlated with the NT2 ice type C/deep snow IC. The spatial and seasonal distributions of the NT2 daily IC retrieval uncertainty provide a useful measure of relative uncertainty, and a direction for further algorithm improvements. Future efforts should focus on the relationship between NT2 IC uncertainties and sea ice types as has been suggested in this paper, particularly the ones employed by the NT2 algorithm. A better understanding of the reasons behind high IC uncertainties will eventually provide insight for improving satellite IC retrievals.

\section{ACKNOWLEDGMENT}

The authors would like to thank three reviewers for their helpful comments and suggestions. The 2010 AMSR-E/Aqua L2A Global Swath Spatially Resampled Brightness Temperatures product (version 10) were distributed by the U.S. National Snow and Ice Data Center.

\section{REFERENCES}

[1] AMSR-E Data User Handbook, Japanese Aerospace Exploration Agency (JAXA), 2009.

[2] T. Markus and D. Cavalieri, "An enhancement of the NASA Team sea ice algorithm," IEEE Trans. Geosci. Remote Sens., vol. 38, no. 3, pp. 13871398, May. 2000.

[3] T. Markus and D. J. Cavalieri, "The AMSR-E NT2 sea ice concentration algorithm: its basis and implementation," J. Remote Sens. Soc. Jpn., vol. 29, no. 1, pp. 216-225, 2009.

[4] D. J. Cavalieri, T. Markus, D. K. Hall, A. J. Gasiewski, M. Klein, and A. Ivanoff, "Assessment of EOS aqua AMSR-E Arctic Sea Ice concentrations using Landsat-7 and airborne microwave imagery," IEEE Trans. Geosci. Remote Sens., vol. 44, no. 11, pp. 3057-3069, Nov. 2006.

[5] J. F. Heinrichs, D. J. Cavalieri, and T. Markus, "Assessment of the AMSR-E Sea Ice-Concentration product at the ice edge using RADARSAT-1 and MODIS imagery," IEEE Trans. Geosci. Remote Sens., vol. 44, no. 11, pp. 3070-3080, Nov. 2006.

[6] R. A. Massom, A. P. Worby, V. I. Lytle, T. Markus, I. Allison, T. Scambos, H. Enomoto, K. Tateyama, T. Haran, J. C. Comiso, A. Pfaffling, T. Tamura, A. Muto, P. Kanagaratnam, and B. Giles, "ARISE (Antarctic Remote Ice Sensing Experiment) in the East 2003: Validation of satellite derived sea ice data products," Ann. Glaciol., vol. 44, no. 1, pp. 288-296, Nov. 2006.

[7] D. J. Cavalieri, T. Markus, D. K. Hall, A. Ivanoff, and E. Glick, "Assessment of AMSR-E Antarctic Winter Sea-Ice concentrations using Aqua MODIS," IEEE Trans. Geosci. Remote Sens., vol. 48, no. 9, pp. 33313339, Sep. 2010.

[8] R. W. Lindsay and J. Zhang, "Assimilation of ice concentration in an ice ocean model," J. Atmos. Ocean. Technol., vol. 23, no. 5, pp. 742-749, May 2006.

[9] M. Shokr and T. A. Agnew, "Validation and potential applications of Environment Canada Ice Concentration Extractor (ECICE) algorithm to Arctic Ice by combining AMSR-E and QuikSCAT observations," Remote Sens. Environ., vol. 128, pp. 315-332, Jan. 2013.

[10] S. Eastwood, C. Rune Larsen, T. Lavergne, E. Nielsen, and R. Tonboe, "Global sea ice concentration reprocessing. Product user manual," EUMETSAT Ocean and Sea Ice Satellite Application Facility, Darmstadt, Germany, Tech. Rep. Doc. ver. 1.3, 2011.

[11] C. Kummerow, "On the accuracy of the Eddington approximation for radiative transfer in the microwave frequencies," J. Geophys. Res., Atmos., vol. 98, no. D2, pp. 2757-2765, Feb. 1993.

[12] G. König-Langlo, "The meteorological data of the Georg-von-NeumayerStation (Antarctica) for 1988, 1990, 1991," Alfred-Wegener-Instiut für Polar und Meeresforschung, Bremerhaven, Germany, 1992, Tech. Rep.

[13] R. S. Fraser, N. E. Gaut, E. E. Reifenstein, and H. Sievering, "Interaction mechanisms-within the atmosphere," in Manual of Remote Sensing, R. G. Reeves, A. Anson, and D. Landen, Eds. Falls Church, VA, USA: American Society of Photogrammetry, 1975, pp. 181-233.

[14] D. T. Eppler, "Microwave remote sensing of Sea Ice," in Geophys. Monogr. 68. Washington, DC, USA: American Geophysical Union, 1992, ch. 4, pp. 47-71, Passive microwave signatures of sea ice.

[15] D. J. Cavalieri, "A microwave technique for mapping thin sea ice," $J$. Geophys. Res., Oceans, vol. 99, no. C6, pp. 12 561-12 572, Jun. 1994. 
[16] X. Dong, B. Xi, K. Crosby, C. N. Long, R. S. Stone, and M. D. Shupe, "A 10 year climatology of Arctic cloud fraction and radiative forcing at Barrow, Alaska," J. Geophys. Res., Atmos., vol. 115, no. D17, p. 17212 , Sep. 2010.

[17] I. V. Gorodetskaya, L.-B. Tremblay, B. Liepert, M. A. Cane, and R. I. Cullather, "The influence of cloud and surface properties on the Arctic Ocean shortwave radiation budget in coupled models," J. Clim., vol. 21, pp. 866-882, Mar. 2008.

[18] T. Kawanishi, T. Sezai, Y. Ito, K. Imaoka, T. Takeshima, Y. Ishido, A. Shibata, M. Miura, H. Inahata, and R. W. Spencer, "The advanced microwave scanning radiometer for the earth observing system (AMSR-E), NASDA's contribution to the EOS for global energy and water cycle studies," IEEE Trans. Geosci. Remote Sens., vol. 41, no. 2, pp. 184194, Feb. 2003

[19] P. Ashcroft and F. Wentz, "AMSR-E/Aqua L2A Global Swath SpatiallyResampled Brightness Temperatures," Nat. Snow Ice Data Center, Boulder, CO, USA, 2006, Tech. Rep., Digital media.

[20] S. Andersen, R. Tonboe, L. Kaleschke, G. Heygster, and L. Pedersen, "Intercomparison of passive microwave sea ice concentration retrievals over the high-concentration Arctic sea ice," J. Geophys. Res., Oceans, vol. 112, no. C8, p. 8004, Aug. 2007.

[21] P. Gloersen and D. J. Cavalieri, "Reduction of weather effects in the calculation of sea ice concentration from microwave radiances," J. Geophys. Res., Oceans, vol. 91, no. C3, pp. 3913-3919, Mar. 1986.

[22] D. Cavalieri, T. Markus, A. Ivanoff, J. Miller, L. Brucker, M. Sturm, J. Maslanik, J. Heinrichs, A. Gasiewski, C. Leuschen, W. Krabill, and J. Sonntag, "A comparison of snow depth on Sea Ice retrievals using airborne altimeters and an AMSR-E simulator," IEEE Trans. Geosci. Remote Sens., vol. 50, no. 8, pp. 3027-3040, Aug. 2012.

[23] C. L. Parkinson and D. J. Cavalieri, "Antarctic sea ice variability and trends, 1979-2010," Cryosphere, vol. 6, no. 4, pp. 871-880, 2012.

[24] J. C. Stroeve, M. C. Serreze, M. M. Holland, J. E. Kay, J. Malanik, and A. P. Barrett, "The Arctic's rapidly shrinking sea ice cover: A research synthesis," Clim. Change, vol. 110, no. 3/4, pp. 1005-1027, Feb. 2012.

Ludovic Brucker received the M.S. degree in physics from the University of Clermont-Ferrand, Clermont-Ferrand, France, in 2006 and the Ph.D. degree from the Laboratoire de Glaciologie et Geophysique de l'Environnement, University of Grenoble Alpes/Centre National de la Recherche Scientifique, Grenoble, France, in October 2009.

He is now with the NASA Goddard Space Flight Center, Greenbelt, MD, USA. His research interests include on the investigation of climate evolution in polar regions by interpreting spaceborne microwave observations of snowcovered surfaces (i.e., sea ice, ice sheet, and terrestrial snowpacks). His work contributes to the comprehension of the relationships between passive microwave airborne and spaceborne observations and snow/ice physical properties using modeling approaches to provide climate-related variables to the community for the satellite era. To that end, he works on developing algorithms and state-of-the-art multilayer snow evolution and emission models. He has also participated in polar deployments in Antarctica, Greenland, and Northern Canada.
Donald J. Cavalieri received the B.S. degree in physics from the City College of New York, New York, NY, USA, in 1964; the M.A. degree in physics from Queens College, Flushing, NY, in 1967; and the Ph.D. degree in meteorology and oceanography from New York University, New York, in 1974.

From 1974 to 1976, he was a National Research Council Postdoctoral Resident Research Associate with the National Oceanic and Atmospheric Administration Environmental Data Service, Boulder, CO, USA, where he continued his doctoral research on stratospheric-ionospheric coupling. In 1979, he joined the Laboratory for Atmospheres, NASA Goddard Space Flight Center, Greenbelt, MD, USA. In 2009, after 30 years of working on sea ice algorithm development and validation for satellite microwave radiometers and on cryospheric system science, he retired as a NASA Senior Research Scientist with the Cryospheric Sciences Branch, Hydrospheric and Biospheric Sciences Laboratory. He continues to work as a Part-Time Consultant within the Cryospheric Sciences Laboratory. His current research interests include the refinement and validation of sea ice algorithms for the Advanced Microwave Scanning Radiometer for Earth Observing System and the development of sea ice climate data records.

Thorsten Markus received the M.S. and Ph.D. degrees in physics from the University of Bremen, Bremen, Germany, in 1992 and 1995, respectively.

He is currently the Head of the Cryospheric Sciences Branch, Hydrospheric and Biospheric Sciences Laboratory, NASA Goddard Space Flight Center, Greenbelt, MD, USA. He is the Project Scientist for ICESat-2. His research interests include satellite and airborne remote sensing of cryospheric, oceanic, and atmospheric processes.

Alvaro Ivanoff received the B.Sc. degree in physics from the University of Toronto, Toronto, ON, Canada, in 1997.

$\mathrm{He}$ is currently working with the NASA Goddard Space Flight Center, Greenbelt, MD, USA, through ADNET Systems, Inc., supporting algorithm development and validation. 